\title{
Oxidative stress and redox signaling in CRPC progression: therapeutic potential of clinically- tested Nrf2-activators
}

\author{
Debasis Mondal, Devin Narwani, Shahnawaz Notta, Dawood Ghaffar, Nikhil Mardhekar, Syed S. A. Quadri
}

Debusk College of Osteopathic Medicine, Lincoln Memorial University, Knoxville, TN 37932, USA.

Correspondence to: Dr. Debasis Mondal, Associate Professor of Microbiology, Debusk College of Osteopathic Medicine, Lincoln Memorial University, 9737 Cogdill Road, Rm. \#238, Knoxville, TN 37932, USA. E-mail: debasis.mondal@Imunet.edu

\begin{abstract}
How to cite this article: Mondal D, Narwani D, Notta S, Ghaffar D, Mardhekar N, Quadri SSA. Oxidative stress and redox signaling in CRPC progression: therapeutic potential of clinically-tested Nrf2-activators. Cancer Drug Resist 2021;4:96-124. http://dx.doi.org/10.20517/cdr.2020.71
\end{abstract}

Received: 31 Aug 2020 First Decision: 23 Oct 2020 Revised: 6 Nov 2020 Accepted: 11 Nov 2020 Available online: 19 Mar 2021

Academic Editor: Godefridus J. Peters Copy Editor: Cai-Hong Wang Production Editor: Jing Yu

\begin{abstract}
Androgen deprivation therapy (ADT) is the mainstay regimen in patients with androgen-dependent prostate cancer (PCa). However, the selection of androgen-independent cancer cells leads to castrate resistant prostate cancer (CRPC). The aggressive phenotype of CRPC cells underscores the need to elucidate mechanisms and therapeutic strategies to suppress CRPC outgrowth. Despite ADT, the activation of androgen receptor (AR) transcription factor continues via crosstalk with parallel signaling pathways. Understanding of how these signaling cascades are initiated and amplified post-ADT is lacking. Hormone deprivation can increase oxidative stress and the resultant reactive oxygen species (ROS) may activate both AR and non-AR signaling. Moreover, ROS-induced inflammatory cytokines may further amplify these redox signaling pathways to augment AR function. However, clinical trials using ROS quenching small molecule antioxidants have not suppressed CRPC progression, suggesting that more potent and persistent suppression of redox signaling in CRPC cells will be needed. The transcription factor Nrf2 increases the expression of numerous antioxidant enzymes and downregulates the function of inflammatory transcription factors, e.g., nuclear factor kappa B. We documented that Nrf2 overexpression can suppress AR-mediated transcription in CRPC cell lines. Furthermore, two Nrf2 activating agents, sulforaphane (a phytochemical) and bardoxolone-methyl (a drug in clinical trial) suppress AR levels and sensitize CRPC cells to anti-androgens. These observations implicate the benefits of potent Nrf2-activators to suppress the lethal signaling cascades that lead to CRPC outgrowth. This review article will address the redox signaling networks that augment AR signaling during PCa progression to CRPC, and the possible utility of Nrf2-activating agents as an adjunct to ADT.
\end{abstract}

\footnotetext{
(ㅇ) (1)

(C) The Author(s) 2021. Open Access This article is licensed under a Creative Commons Attribution 4.0 International License (https://creativecommons.org/licenses/by/4.0/), which permits unrestricted use, sharing, adaptation, distribution and reproduction in any medium or format, for any purpose, even commercially, as long as you give appropriate credit to the original author(s) and the source, provide a link to the Creative Commons license, and indicate if changes were made.
}

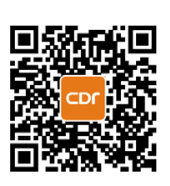


Keywords: Prostate cancer, androgen receptor, hormone therapy, endocrine resistance, oxidative stress, redox signaling, Nrf2, Nrf2-activators

\section{INTRODUCTION}

Despite multiple treatment strategies that are currently available against prostate cancer (PCa), it remains the second leading cause of cancer-associated deaths in elderly Caucasian men in the United States ${ }^{[1]}$. Furthermore, individuals of African descent show a 2-fold higher risk of developing PCa at an earlier age and manifest higher morbidity and mortality associated with advanced and metastatic disease ${ }^{[2]}$. Interestingly however, both the incidence of $\mathrm{PCa}$ and its pathologic progression are significantly lower in Orientals and other Asian populations ${ }^{[3,4]}$, suggesting that in addition to age and race, both epigenetics and diet may play important roles in regulating the initiation and progression of $\mathrm{PCa}^{[5-8]}$. Common underlying factors associated with these traits, i.e., age, race and diet, are differences in oxidative stress and antioxidant capacities in different populations, and their susceptibility to aggressive cancer growth. Indeed, clinical evidence of faster PCa disease progression in obese individuals further corroborates the hypothesis that oxidative stress and inflammation, often documented in adipose tissues, are key players in the initiation, progression and therapeutic resistance of $\mathrm{PCa}^{[9,10]}$. There are numerous review articles that have addressed the roles of inflammatory cytokines and reactive oxygen species (ROS) in PCa initiation and progression ${ }^{[11-14]}$. Therefore, this review article will focus on the significance of oxidative stress, inflammation and the redox signaling networks, which enable endocrine resistance and the outgrowth of castration resistant prostate cancer (CRPC).

Although numerous groups are currently working on this topic, a clear molecular pathway of how progression from hormone-dependent PCa cells to hormone-independent CRPC cells inevitably occurs in patients, is not thoroughly understood ${ }^{[15-17]}$. Indeed, the precise mechanism and the molecular steps involved in both the persistence and amplification of androgen receptor (AR) signaling, which facilitate the recurrence of PCa despite hormone deprivation, needs to be fully explored and elucidated. Since resistance to androgen deprivation plays a critical role in dictating long-term survival of PCa patients, the development of more effective treatment strategies to decrease the selection and outgrowth of CRPC cells, and especially, their lethal progression to metastatic CRPCs (mCRPC) will be of significance ${ }^{[18,19]}$.

We discuss the deleterious consequences of sudden hormone (androgen) deprivation in inducing oxidative stress in both PCa cells and the tumor microenvironment. Inflammatory cytokines secreted within this activated tumor microenvironment may further amplify these redox signaling networks and crosstalk with the AR signaling pathway, to enable a persistent mitogenic activation of PCa cells and the selection of CRPC ${ }^{[20]}$. The crucial role of interleukin-6 (IL-6), an inflammatory cytokine that is often upregulated in $\mathrm{PCa}$ patients and activates several inflammatory transcription factors like nuclear factor kappa B (NF- $\kappa \mathrm{B})$ and signal transducers and activators of transcription (STAT), will also be evaluated ${ }^{[21]}$. In addition, we will discuss the therapeutic potential of a master regulator of oxidative stress, the Nrf2-transcription factor and its antagonism of NF- $\mathrm{KB}$, towards the resolution of oxidative stress and suppression of CRPC progression post hormone deprivation ${ }^{[22]}$. Below, we provide a short overview of PCa initiation, progression and therapeutic resistance, followed by a more thorough discussion of signaling via the AR transcription factor and its crosstalk with multiple redox signaling networks, e.g., IL-6. A short description of the oxidants and antioxidants is provided next, focused at the crucial function of Nrf2 transcription factor. Lastly, the potential of Nrf2-activating agents in suppressing CRPC outgrowth in PCa patients, will be discussed.

\section{PROSTATE CANCER: INITIATION, PROGRESSION AND THERAPY}

The prostate gland is a pseudostratified organ that provides nutrients to sperm. It also produces an alkaline prostatic fluid which helps in liquefaction of the seminal plug and neutralization of the acidic 
vaginal environment ${ }^{[23]}$. Circumstances that result in chronic oxidative stress and inflammation within prostatic microenvironments, such as aging, carcinogens, diet, obesity and genetic dysfunctions, may lead to increased cell growth (benign prostate hyperplasia or BPH) or the prostate epithelial cells may undergo oncogenic reprogramming to generate carcinomas of the prostate ${ }^{[24]}$. Prostate-specific antigen (PSA), an enzyme that helps liquefaction of semen, is a surrogate marker of both BPH and PCa growth, and increased serum levels of PSA is utilized for detecting early stage $\mathrm{PCa}^{[25]}$. However, several problems with PSA screening, especially with its inability to distinguish between BPH and PCa, has been a challenge in the clinical setting ${ }^{[26]}$. In addition to serum PSA levels, PCa is further confirmed by digital rectal exam and needle biopsy ${ }^{[27,28]}$. If confirmed at an early stage, the localized, organ confined prostate tumors can be successfully removed by prostatectomy or eliminated by radiotherapy ${ }^{[24,29]}$. Pathologic analysis of tumor sections from core needle biopsies can also be used to positively determine the histologic characteristics and stage of the cancer ${ }^{[30]}$. The Gleason grading system is commonly used to determine whether the tumor nodes are indolent, where an approach towards passive monitoring or "watchful-waiting" may be implemented. If the stained prostate cores are determined to be highly cellular, invasive and aggressive, rapid ablative therapy is necessary for therapeutic success. In this respect, a Gleason score (GS) of less than six $(G S \leq 6$ or $3+3)$ represents slow growing and androgen responsive tumors, whereas more aggressive tumors show a GS $\geq 7$ (either $3+4$ or $4+3$ ), which represent tumors having metastatic potential and a higher capacity to progress towards endocrine resistance ${ }^{[29,31]}$. Therefore, a precise diagnosis of indolent $v s$. aggressive PCa will decide the therapy to be implemented ${ }^{[32]}$.

Endocrine therapy, which uses different strategies to suppress the mitogenic action of androgens, is paramount to slow down aggressive tumor growth ${ }^{[32-34]}$. Androgens are steroid hormones produced by the adrenal glands and the testes, which are crucial in the mitogenic stimulation of PCa cells ${ }^{[35-37]}$. Therefore, $\mathrm{ADT}$ is the mainstay regimen in patients with aggressive or recurrent $\mathrm{PCa}^{[38]}$. To date, four different forms of ADT are clinically approved in patients ${ }^{[39-41]}$ : (1) surgical removal of the testes or orchiectomy; (2) inhibitors of the CYP17 enzyme, to suppress the synthesis of androgens; (3) administration of luteinizing hormone-releasing hormone analogues/agonists to decrease adrenal steroid hormone synthesis; and (4) the use of antiandrogens, which diminish the ligand-mediated activation of AR transcription factor. However, despite the early success of ADT, cancer cells can still undergo molecular alterations and select for cells with a CRPC phenotype ${ }^{[17,20,42]}$. A schematic of PCa initiation, progression and therapeutic resistance is presented in Figure 1.

A rising serum PSA level, which is an AR-dependent gene product, is often an indicator of tumor recurrence in individuals following ADT. At this point, a second-generation AR antagonist, such as enzalutamide, is recommended to fully abrogate persistent AR signaling in CRPC cells ${ }^{[43,44]}$. However, despite its potency to suppress AR function, enzalutamide has only shown limited improvement in the long-term survival of patients ${ }^{[45]}$. In recent years, ADT along with low-dose chemotherapy, e.g., docetaxel, has been prescribed to patients in whom prostatectomy or radiotherapy have failed ${ }^{[46]}$. Interestingly, several recent studies have also shown that, in lieu of endocrine therapy, initiation with late-stage chemotherapy, e.g., docetaxel or cabazitaxel, in combination with prednisone ${ }^{[47]}$ or a combination of immunotherapy (sipuleucel T) and radiotherapy (Radium-223) can be used to suppress progression to high grade tumors and to decrease the possibility of endocrine resistance development ${ }^{[48,49]}$. These observations suggest that current hormone deprivation strategies for early stage PCa may need to be restructured, and their utility in CRPC patients may need to be fully rationalized.

\section{AR SIGNALING, HORMONE DEPRIVATION AND CRPC OUTGROWTH}

Decreased growth of PCa cells can be achieved by stopping the mitogenic actions of several male hormones, such as androgen, testosterone and dihydro-testosterone (DHT), the binding of which increases nuclear localization and the transactivation function of $\mathrm{AR}^{[50,51]}$. The $\mathrm{AR}$ transcription factor belongs to 


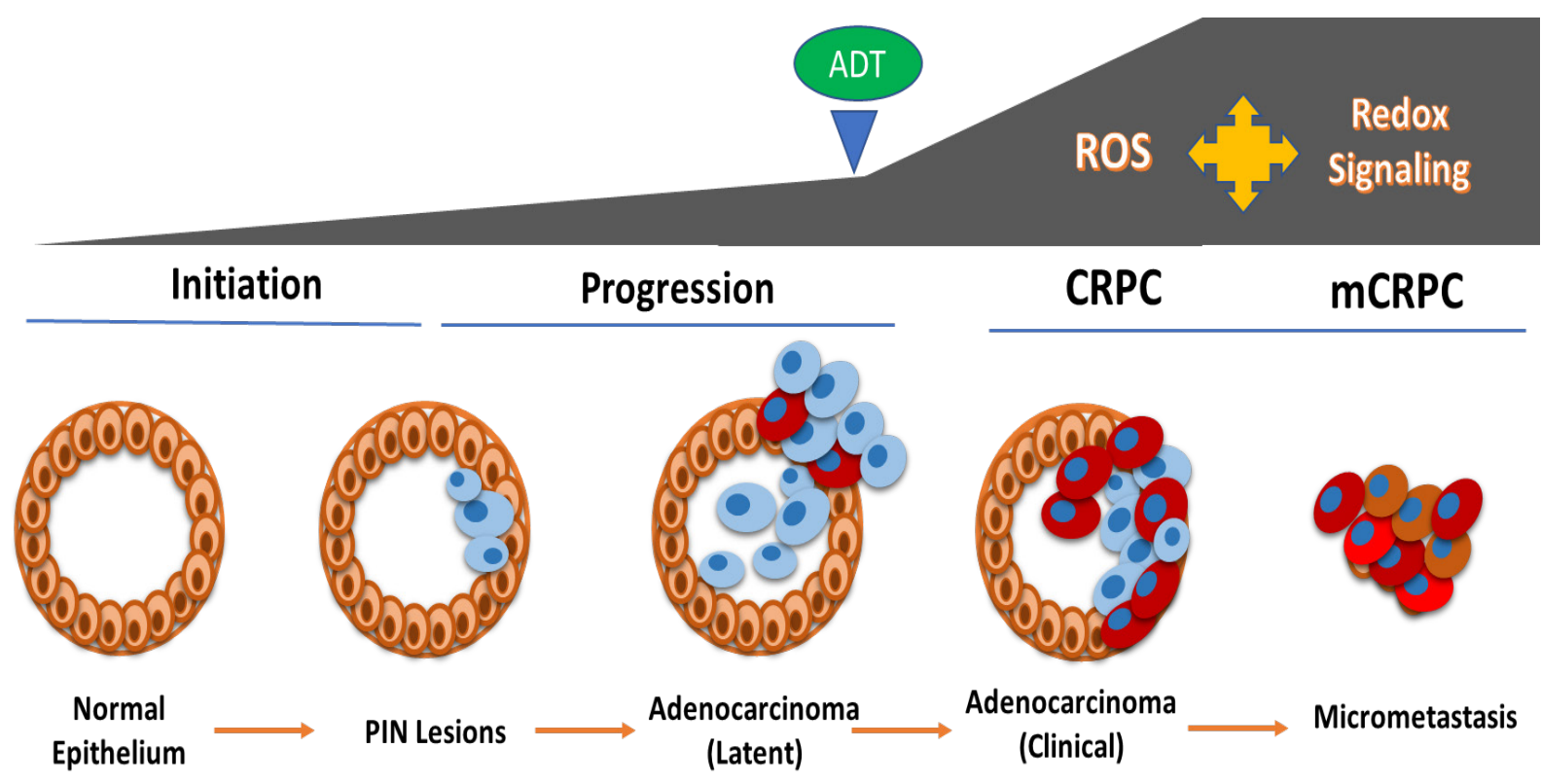

Figure 1. Increased oxidative stress, ROS production and redox signaling during PCa progression. A schematic representation of the prostate gland is shown on the left. Neoplastic transformation of the normal epithelium leads to PIN lesions, which progress to localized adenocarcinoma and depends on androgen and AR signaling for growth. Administration of ADT causes hormone-deprivation-induced oxidative stress, ROS production and amplified redox signaling networks in PCa cells, which facilitates the selection of CRPC cells. These aggressive CRPC cells can then metastasize to distant sites to form mCRPC, which dictates morbidity and mortality in patients. PCa: prostate cancer; ADT: androgen deprivation therapy; ROS: reactive oxygen species; CRPC: castrate resistant prostate cancer; $\mathrm{mCRPC}$ : metastatic CRPCs

the family of steroid hormone receptors, and AR, a ligand (androgen) activated nuclear transcription factor that remains crucial to the growth of both PCa cells and CRPC cells ${ }^{[52]}$. Persistent AR signaling also seems to facilitate the metastasis of CRPC cells (mCRPC) ${ }^{[53]}$. Briefly, the AR protein has three major functional domains: (1) a N-terminal transactivation domain that associates with numerous transcriptional coactivators; (2) a DNA binding domain that recognizes the androgen response element (ARE); and (3) a C-terminal domain (LBD) which binds to chaperones and ligands. In androgen-dependent PCa cells, the AR protein is mostly found in the cytoplasm bound to its chaperone heat shock proteins (HSP) Hsp40 and $\mathrm{Hsp}_{70}{ }^{[54]}$. Following ligand binding, a conformational change in AR leads to its dissociation from these chaperones, resulting in its nuclear translocation. Once inside the nucleus, AR dimerizes and binds to its DNA binding element (ARE) and augments the transcription of multiple genes that are necessary for PCa survival, growth and invasion ${ }^{[55-57]}$. Many of the currently available antiandrogens attenuate AR signaling by competing with androgens for AR binding ${ }^{[58]}$ and may also be effective in suppressing the recruitment of coactivators or by activating corepressors ${ }^{[59-61]}$. Therefore, in androgen-dependent PCa cells, ligand-mediated activation of AR can be downregulated by multiple hormone deprivation strategies that are implemented during $\mathrm{ADT}^{[62]}$ and their biochemical failure enables tumor recurrence and distant metastasis $^{[63]}$. Both canonical and non-canonical pathways of AR activation are shown below [Figure 2].

Despite the initial efficacy of ADT, the surviving cells show a persistent and often, an amplified AR signaling axis. Numerous studies have shown that an amplification of ligand-independent AR signaling occurs due to numerous crosstalk between AR and parallel non-AR signaling pathways ${ }^{[1720,42,64-66]}$. Therefore, strategies to suppress both AR and non-AR signaling would be needed to ultimately suppress the outgrowth of CRPC cells. Both in vitro and in vivo studies have shown that the CRPC cells remain fundamentally dependent on AR gene expression, and their ability to sustain functional AR signaling has been linked to several different mechanisms: (1) amplification of the AR gene; (2) gain of function mutations of the AR gene; (3) intratumoral androgen production; (4) ligand independent activation of AR proteins; and (5) the expression of 


\section{Ligand Dependent AR Activation}

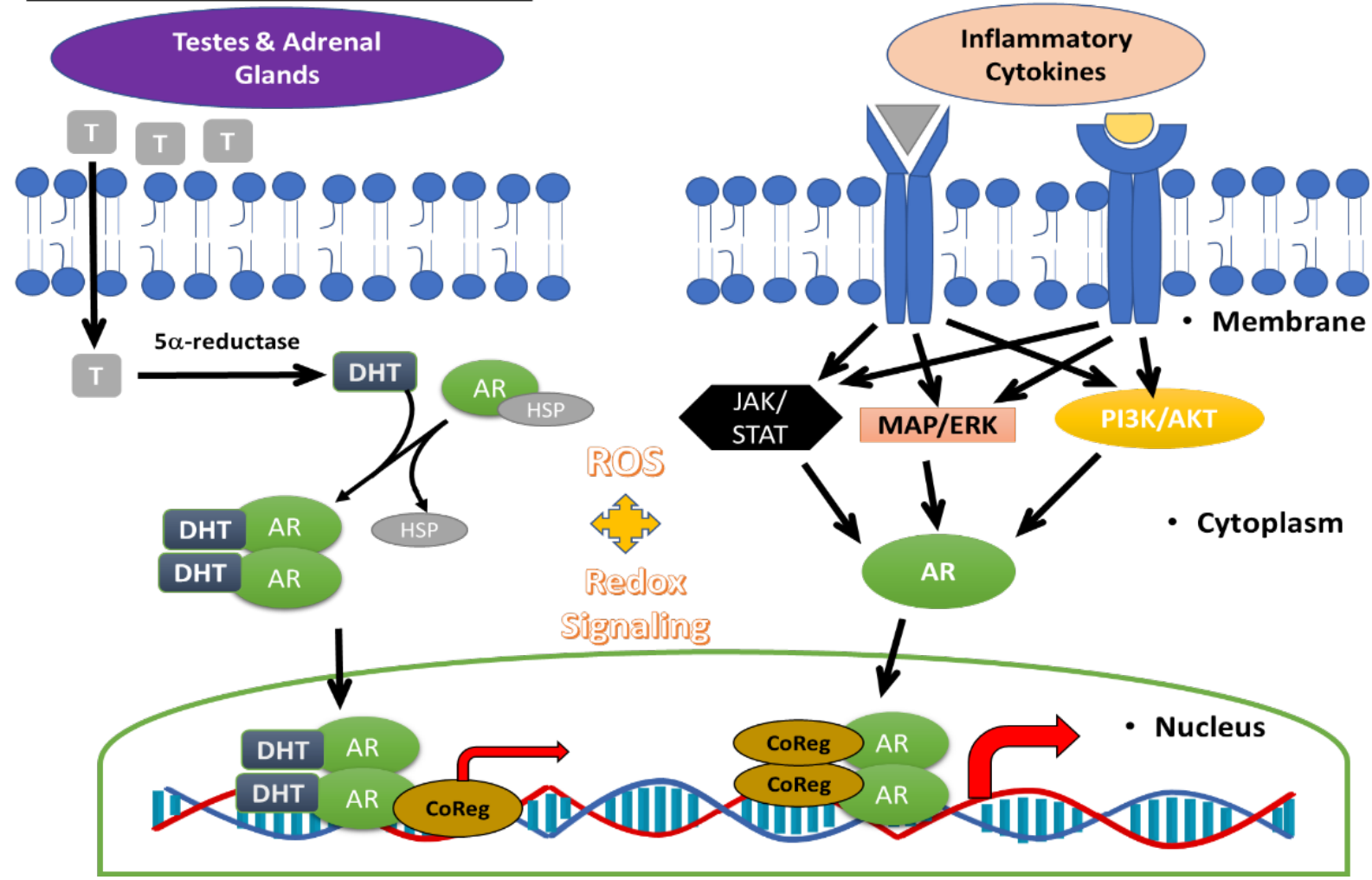

Figure 2. Signaling via AR occurs by both ligand-dependent and ligand-independent mechanisms. The male steroid hormones, androgen and testosterone $(T)$ are produced by the testes and adrenal glands and manifest their endocrine effects on PCa cells via liganddependent activation of AR signaling (left). Inside the PCa cells, $\mathrm{T}$ is converted to a highly potent analog dihydrotestosterone (DHT) by the $5 \alpha$-reductase enzyme. DHT binding to AR releases it from its chaperone, the heat shock proteins (Hsp). The activated AR then dimerizes and translocates to the nucleus, where it recruits coregulators of transcription to increase PCa growth. Ligand-independent activation of AR (right) can also occur due to multiple signaling pathways, primarily activated by inflammatory cytokines, and utilize ROS as second messengers. Therefore, amplified redox signaling networks can facilitate non-AR signaling, resulting in CRPC outgrowth post hormone deprivation. AR: androgen receptor; PCa: prostate cancer; ROS: reactive oxygen species; CRPC: castrate resistant prostate cancer

constitutively active AR splice variants ${ }^{[17,20,67,68]}$. The ataxia-telangiectasia-mutated (ATM) protein is a key regulator of the DNA damage response following oxidative stress. Interestingly, exposure to AR antagonists induces both telomere DNA damage and damage response inhibition in the CRPC cell line $22 \mathrm{Rv} 1^{[69]}$. Combined exposure to enzalutamide and the ATM inhibitor, KU60019, significantly inhibits cell survival in vitro and tumor growth in vivo ${ }^{[69]}$. Most interestingly, our recent in vitro findings ${ }^{[70,71]}$ also showed that coexposure to potent antioxidants, such as the phytochemical sulforaphane ${ }^{[70]}$ and the synthetic compound, bardoxolone-methyl (CDDO-me $)^{[71]}$ can also sensitize these $22 \mathrm{Rv} 1$ cells to the anti-proliferative effects of enzalutamide. Therefore, studies suggest that adjuvant therapies with potent antioxidants may be able to increase the efficacy of ADT.

\section{CONSTITUTIVE AR SIGNALING IN PCA CELLS DESPITE ANDROGEN DEPRIVATION}

Multiple investigations have demonstrated the importance of AR signaling in CRPC cells, where constitutively high nuclear AR protein levels were observed in both CRPC cell lines grown in the absence of hormone stimulation ${ }^{[72]}$ and in both tumor samples from patients undergoing $\mathrm{ADT}^{[68]}$ and in circulating tumor cells (CTC) from CRPC patients ${ }^{[73]}$. However, little is known about the exact mechanism(s) that causes PCa cells to persistently activate a potent level of AR expression and signaling that enable increased nuclear AR levels. Frequently, it has been documented that PCa cells that manifest even a partial resistance 
to hormonal therapy show upregulation of factors linked with cell survival ${ }^{[74]}$ and downregulation of proteins associated with apoptosis ${ }^{[75,76]}$. Therefore, it is hypothesized that CRPC outgrowth occurs due to a significant shift in gene expression profile of the surviving PCa cells that have the potential to be more aggressive and can overcome the initial insult of hormone deprivation ${ }^{[77,78]}$. It has also been suggested that these initial CRPC cells can use residual levels of hormones that are secreted from adrenal and/or prostatic sources, which enable them to persistently activate AR signaling ${ }^{[6,79]}$. In addition, it is also evident that CRPC cells may also start expressing enzymes required for the de novo synthesis of testosterone and other steroid metabolizing enzymes that facilitate the conversion of androgens to the highly potent form, $\mathrm{DHT}^{[80]}$. Another key factor, often documented in CRPC tumors from patients, involves the expression of spliced isoforms of AR, which lack the LBD and hence, become constitutively activated ${ }^{[67,81]}$. In this respect, AR-V7 (also known as AR3) is recognized as a major splice variant in CRPC cells, both in solid tumor specimens and in circulating tumor cells ${ }^{[82]}$. Indeed, increased AR-V7 levels have often been associated with a worse prognosis in PCa patients ${ }^{[25,83]}$. Intriguingly, the AR-V7 protein, and its constitutive activation and nuclear levels, were also shown to support epithelial-to-mesenchymal transition of PCa cells, underscoring its importance as a predictive biomarker of aggressive disease and therapeutic resistance ${ }^{[84]}$. However, the precise mechanisms that control the above documented changes in AR signaling to overcome the initial effects of hormone deprivation are still not fully elucidated ${ }^{[85-87]}$.

Essentially, denying PCa cells of their preferred growth signaling results in a sudden change within the tumor microenvironments and induces oxidative stress. Changes in the behavior of the PCa cells undergoing $\mathrm{ADT}$ is likely due to an adaptive response to a combination of stresses from the hypoxic tumor environment, which results in the activation of multiple alternate second messenger signaling that increase both AR gene expression and ligand-independent AR activation ${ }^{[88,89]}$. Inflammatory cytokines produced within this microenvironment may further amplify second messengers via ROS and intensify redox signaling and crosstalk that enable progression to androgen independence. Indeed, recent findings show that androgen-induced expression of dynamin-related protein 1 (Drp1) can regulate mitochondrial function in PCa cells ${ }^{[90]}$, thus providing evidence of a vicious cycle of ROS production, inflammation and redox signaling amplification. Both in vitro and in vivo studies have demonstrated that changes in the activity of various cofactors that modify AR signaling can support its crosstalk with multiple, parallel signal transduction pathways involved in CRPC progression ${ }^{[1-96]}$. Indeed, endocrine resistance has often been associated with elevated levels of pro-inflammatory cytokines, such as interleukins (ILs) like IL-6 and IL-8, tumor necrosis factor-alpha (TNF- $\alpha$ ), macrophage chemotactic factor-1 and several transforming growth factor (TGF) family of proteins like TGF-b1 and Activin. Furthermore, changes in downstream transcription factors, e.g., NF- $\kappa \mathrm{B}$, STATs and CCAAT/Enhancer binding protein-beta (C/EBP- $\beta$ ), which are often activated by the above mentioned inflammatory mediators, have also been implicated in augmenting AR function ${ }^{[97-100]}$. The invasive PCa cells may metastasize to tissue sites in which tumor hypoxia and changes in tumor vascularization may further upregulate oxidative stress and redox signaling ${ }^{[101,102]}$. These observations underscore the importance of signaling crosstalk in CRPC progression.

Novel strategies to suppress the outgrowth of CRPCs may be developed by using inhibitors of specific inflammatory signaling pathways or by using potent antioxidants, primarily as an adjunct to the currently available ADT regimens. An inflammatory cytokine that is of crucial importance in this respect is interleukin 6 (IL-6), which is significantly increased in aggressive tumor microenvironments ${ }^{[21,91]}$. Furthermore, evidence of differential IL- 6 signaling in hormone-dependent and -independent PCa cells $^{[103,104]}$ and therapeutic implications of IL- 6 antagonism to suppress CRPC progression ${ }^{[99,105,106]}$. Therefore, we are providing below a short overview of IL- 6 signaling and its role in increasing oxidative stress and redox signaling in the CRPC cells. 


\section{INTERLEUKIN-6 IN REDOX-SIGNALING AMPLIFICATION IN CRPC CELLS}

IL-6 is a very important cytokine with respect to its potential to enhance both AR and non-AR signaling in PCa cells. It is primarily produced in response to tissue injury, inflammation, and oxidative stress ${ }^{[107]}$. In addition to its role in regulating immune cell function against cancer cells, it plays a crucial function in cancer survival and pathophysiology ${ }^{[1,103,108]}$. Androgen deprivation in mice by orchidectomy was shown to increase serum IL- 6 levels and IL- 6 mRNA expression in the bone marrow cells ${ }^{[109]}$. IL-6 is also able to promote the growth of hormone-dependent prostate cancer cells in castrated mice ${ }^{[10]}$. Circulating levels of IL- 6 were found to be increased in patients with metastatic CRPC ${ }^{[111]}$ and its circulating levels correlated with poor prognosis in PCa patients ${ }^{[122]}$. Indeed, both IL-6 and IL6-receptor alpha (IL-6R $\alpha$ ) can be synthesized by PCa cells and their expression is enhanced in aggressive tumors ${ }^{[113]}$. Therefore, the above findings implicate IL-6 signaling as a key player in the persistent AR signaling and activation in cells with a CRPC phenotype.

Second messenger signaling via IL- 6 has been well reviewed in several past publications ${ }^{[114,115]}$. Briefly, IL-6 signaling is initiated by its binding to the cell membrane receptor IL-6R (gp80 subunit) which facilitates dimerization with the signal transducing subunit (gp130). Multiple downstream signaling cascades are activated following IL-6R $\alpha$ activation, and many of these utilize ROS second messengers ${ }^{[116,117]}$. Following ligand binding, the receptor-associated Janus associated kinase (JAK) then activates gp130 and helps it to serve as a docking site for the STAT transcription factors. Indeed, IL- 6 can simultaneously activate three distinct signal transduction pathways, which include (1) JAK/STAT signaling, especially via STAT3; (2) the mitogen-activated protein kinases/extracellular signal-regulated kinase (MAP/ERK) cascade; and the (3) phosphatidylinositol 3-kinase/protein kinase B (PI3K/AKT) cascade. These activated second messengers facilitate the stabilization, dimerization and nuclear translocation of multiple transcription factors, thus regulating many target genes ${ }^{[117]}$. A simplified version of the IL- 6 signaling cascades is shown below in Figure 3.

Interestingly, during the early stages of carcinogenesis, high levels of circulating IL-6 may play a preventive role in tumor progression by activating basal transcription factors such as specificity protein $1(\mathrm{Sp} 1)$ and CCAAT enhancer binding protein beta (C/EBP- $\beta$ ), also known as nuclear factor for IL-6 (NF-IL6), but during late stages of aggressive growth, IL- 6 signaling may help cancer cells become more resistant to ablative therapy by inducing inflammatory transcription factors such as STAT and NF- $\kappa B^{[118-120]}$. Several studies have also shown that a number of transcription factors, e.g., NF- $\mathrm{B}$, STAT and C/EBP, which are activated during IL- 6 signaling, can directly interact with AR and regulate its function ${ }^{[121-124]}$. In the aggressively growing CRPC cells, where a state of epigenetic transformation is found to be critical, activation of IL- 6 and the downstream signaling to activate STAT3, PI3K and MAPK, and ultimately the nuclear translocation of NF- $\kappa \mathrm{B}$ have been documented ${ }^{[125]}$. Altholactone, a natural compound isolated from Goniothalamus spp., inhibited both NF- $\mathrm{BB}$ and STAT3 activation and induced ROS-mediated apoptosis in $\mathrm{PCa} C \mathrm{Clls}^{[126]}$. The resistance of CRPC cells to antiandrogens was overcome by targeting NF- $\mathrm{BB}$ signaling using artesunate $e^{[127]}$. This study highlighted the combination of NF- $\mathrm{BB}$ inhibitors and AR antagonists may potentiate the clinical efficacy of ADT in CRPC patients. Furthermore, this combination reduced NF- $\kappa B$ signaling and decreased the expression of both $\mathrm{AR}$ and $\mathrm{AR}-\mathrm{V} 7$. These studies demonstrate the importance of targeting NF- $\mathrm{BB}$ and IL- 6 to suppress CRPC progression.

Most interestingly, although the androgen-dependent PCa cell line (LNCaP) starts dying within a few days under hormone deprived conditions (charcoal stripped serum), these cells rapidly become resistant when cultured in presence of recombinant IL-6. Similarly, the selectivity of the CRPC phenotype was also evident in LNCaP cells transfected with a constitutively active STAT3 expression vector ${ }^{[128,129]}$. Therefore, based on the crucial role of IL-6/JAK/STAT3/NF- $\mathrm{B}$ signaling in CRPC outgrowth, one could assume that the targeting of IL-6 signaling would be an ideal approach. Although Phase-I clinical studies with a chimeric 


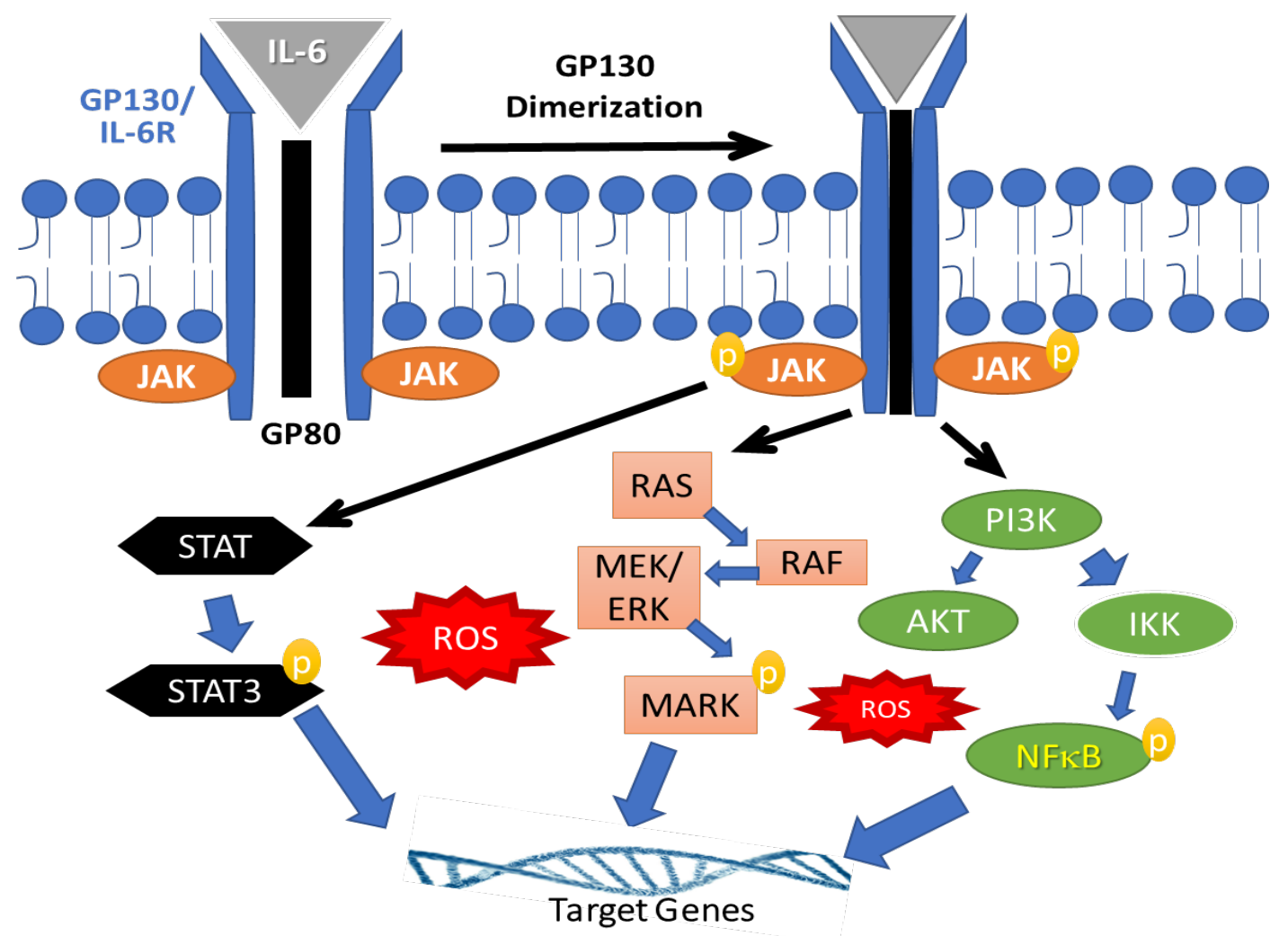

Figure 3. Multiple signaling cascades are activated following IL-6 binding to its receptor (GP130). Ligand binding causes GP130 dimerization and activation (phosphorylation) of the associated JAK kinase, which then activates downstream STAT transcription factor. GP130 activation can also transduce second messenger signaling via the RAS/RAF/MEK/ERK pathway to activate MAP kinase (MAPK). In addition, this inflammatory cytokine can also initiate the PI3K signaling at the membrane, which can either activate IKB kinase (IKK) and thus enhance NF- $\mathrm{KB}$ transcription factor function or PI3K may activate the downstream protein kinase B (AKT) which suppress NF$\kappa B$ activation. Therefore, IL-6 signaling activates multiple redox signaling networks that may crosstalk with AR and activate it in a ligandindependent manner. IL-6: interleukin-6; JAK: Janus associated kinase; STAT: signal transducers and activators of transcription; NF- $\mathrm{B}$ : nuclear factor kappa B

monoclonal antibody against IL-6, Siltuximab (CNTO328) combined with docetaxel, showed some promise in delaying disease progression in patients with mCRPC ${ }^{[105]}$, Phase-II results were not as promising ${ }^{[130]}$. Furthermore, studies involving monotherapy with Siltuximab have not yielded significant positive results in PCa patients ${ }^{[131]}$. Therefore, in accordance with current scientific evidence of the crucial role of continuous redox signaling crosstalk in CRPC cells, the use of antioxidants may provide a more promising approach. Therefore, to assist the reader's understanding, we are providing a brief overview of pro-oxidants and antioxidants below.

\section{OXIDATIVE STRESS, REACTIVE OXYGEN SPECIES AND ANTIOXIDANTS}

Reactive oxygen species (ROS) are produced during aerobic metabolism in cells and are most often generated during the conversion of glucose into adenosine triphosphate (ATP) via the tricarboxylic acid (TCA) cycle and the mitochondrial electron transport complex (ETC $)^{[132]}$. A dysfunctional or overwhelmed ETC can result in the leakage of electrons, which are captured by molecular oxygen $\left[\mathrm{O}_{2}\right]$ to ultimately generate free oxygen radicals such as the superoxide anion $\left(\mathrm{O}_{2}{ }^{-}\right)$, hydrogen peroxide $\left(\mathrm{H}_{2} \mathrm{O}_{2}\right)$, and hydroxyl radicals $(\mathrm{OH} \cdot)^{[133]}$. Chronic exposure to high levels of these ROS can cause significant damage to DNA, proteins and lipids, and ultimately result in decreased antioxidant defense mechanisms ${ }^{[134]}$. In addition to the mitochondria, another cellular organelle often involved in ROS production is the endoplasmic reticulum (ER) where proteins are translated from cellular messenger RNAs (mRNAs). A third candidate 
for ROS generation, at both the plasma membrane and the nuclear membrane, are $\mathrm{NAD}(\mathrm{P}) \mathrm{H}$ oxidase (NOX) enzymes, which produce ROS in response to inflammatory stimuli and act as carriers of electrons to the ETC within the mitochondria. Studies have shown that the beneficial or detrimental effects of oxidative stress are contingent upon the genetics of the cell, the kind of ROS involved, the duration and levels of ROS being generated, and the ability of cells to replenish their antioxidant capacity. Therefore, optimal regulation of oxidative stress within different parts of the cell is critical in maintaining the redox balance.

Oxidative stress results in ROS-mediated second messenger signaling, which increases the production of inflammatory cytokines and creates a feed-forward loop to generate more ROS and amplified redoxsignaling ${ }^{[135]}$. In highly proliferative cancer cells, and especially in cells undergoing sudden changes in their microenvironments such as hormone deprivation or hypoxic conditions, the ER is susceptible to proteotoxic stress ${ }^{[136]}$. Under physiologic conditions, an unfolded protein response regulates protein stability via the proteasome. However, under pathologic conditions, the resultant ER-stress and altered ERmitochondria homeostasis then cause the production of ROS and oxidative stress ${ }^{[137-139]}$. Communication between mitochondria and other organelles is also being documented ${ }^{[139]}$. Therefore, these ER-mitochondria contact sites are crucial in ROS generation, redox signaling and therapeutic resistance.

An intricate antioxidant defense system counterbalances the constant production of reactive oxidants by the aggressive prostate cancer cells ${ }^{[140]}$. These highly complex webs of oxidation-reduction cycles consist of donor-acceptor reactions, which ensure that the response to reactive oxidants is adequate, for both the immediate signaling needs of the cell while decreasing the long-term deleterious consequences of ROS. Therefore, ROS generated via different reactions are promptly quenched within the close vicinity of their intracellular microenvironments. Oxidative stress occurs when there is an imbalance in the regulation of ROS production and the replenishment of required antioxidant levels. In this respect, the first line of defense against ROS are the small molecule antioxidants such as glutathione (GSH), vitamin C (Ascorbic acid; AA) and vitamin $\mathrm{E}$ (Tocopherol) which contribute to immediate antioxidant capacity of the cell ${ }^{[141]}$, and hence, has been most often investigated towards anticancer therapy ${ }^{[142,143]}$. These small molecules scavenge ROS and prevent them from catalyzing the production of other free radicals that propagate the damage to cellular components such as DNA, protein and lipids. In addition, the peroxiredoxins (Prx) and thioredoxins (Trx) are responsible for chelating transition metals that facilitate $\mathrm{OH}^{*}$ production via the Fenton and Haber-Weiss reactions ${ }^{[144]}$. The $\operatorname{Trx}-\operatorname{Tr} x$ reductase (TrxR) system also helps to maintain a reducing environment by catalyzing electron flux from nicotinamide adenine dinucleotide phosphate (NADP). Last but not the least, the regeneration of antioxidant capacities of all of these small molecules are brought about by an interacting network of redox cycles, most importantly the GSH - GSH peroxidase (Gpx) cycle that is pivotal in maintaining cellular redox homeostasis. Several past review articles have addressed the crucial role of the GSH - Gpx axis as well as the importance of the enzymes Gpx and GSH synthase in regulating tumor initiation, progression and therapeutic resistance ${ }^{[145,146]}$. Therefore, in addition to the small molecule antioxidants, studies are now focusing on the therapeutic potential of several of the antioxidant enzymes $^{[147]}$. Decades of research has been done on the most crucial redox regulatory enzymes, superoxide dismutase (SOD) and catalase (CAT) which inactivate $\mathrm{O}_{2}{ }^{-}$and $\mathrm{H}_{2} \mathrm{O}_{2}$ respectively, and their ability to rapidly quench these highly reactive oxidants. Furthermore, numerous recent studies have demonstrated the importance of numerous other antioxidant enzymes as well, such as TrxR, Gpx, heme oxygenase-1 (HO-1), Glutamate cysteine ligase catalytic (GCLc), NADPH Quinone oxidoreductase enzyme (NQO1) etc., the expressions of which are regulated by the master regulatory transcription factor, nuclear factor E2-related factor $2(\mathrm{Nrf} 2)^{[148-150]}$. Indeed, us ${ }^{[150,151]}$ and others ${ }^{[152,153]}$ are discovering the multifaceted functions of Nrf2 in regulating tumor initiation, progression and therapeutic resistance. Since redox reactions play key roles as potent second messengers in many signaling pathways, a short list of the important oxidants and antioxidants, along with their respective enzymatic machinery and symbols, is provided in Table 1. 
Table 1. Reactive oxidants and the ROS quenching antioxidants

\begin{tabular}{ll}
\hline Oxidants and antioxidants & Symbol $^{\mathbf{a}}$ \\
\hline A. Radical ROS & \\
Superoxide & $\mathrm{O}_{2}$ \\
Hydroxyl radical & $\mathrm{OH}$ \\
Nitric oxide & $\mathrm{NO}$ \\
Organic radical & $\mathrm{R}$ \\
Peroxyl radical & $\mathrm{ROO}$ \\
Alkoxyl radical & $\mathrm{RO}$ \\
Thiyl radical & $\mathrm{RS}$ \\
B. Non-radical ROS & \\
Hydrogen Peroxide & $\mathrm{H}_{2} \mathrm{O}_{2}$ \\
Singlet Oxygen & $\mathrm{O}_{2}$ \\
Ozone trioxygen) & $\mathrm{O}_{3}$ \\
Organic hydroperoxide & $\mathrm{ROOH}$ \\
Hypochlorous acid & $\mathrm{HOCL}$ \\
Peroxynitrite & $\mathrm{ONOO}$ \\
C. Enzymatic system & \\
Superoxide Dismutase & $\mathrm{SOD}$ \\
Catalase & $\mathrm{CAT}$ \\
Glutathione Peroxidase & $\mathrm{GPx}$ \\
Glutathione Reductase & $\mathrm{GR}$ \\
Glutathione S-transferase & $\mathrm{GST}$ \\
Thioredoxin Peroxidase & $\mathrm{TrxPx}$ \\
Thioredoxin Peroxidase & $\mathrm{Trxr}$ \\
D. Non-enzymatic system & \\
Glutathione & $\mathrm{GSH}$ \\
Glutaredoxin & $\mathrm{Grx}$ \\
Thioredoxin & $\mathrm{Trx}$ \\
Peroxiredoxin & $\mathrm{Prx}$ \\
Sulfiredoxin & $\mathrm{Srx}$ \\
Vitamins A, C, E & \\
\hline & \\
&
\end{tabular}

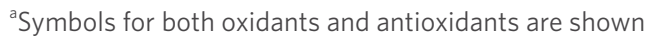

\section{IS THERE A THERAPEUTIC BENEFIT OF ANTIOXIDANTS IN CRPC PROGRESSION?}

The initial focus of oxidative stress and ROS has been mostly directed towards their deleterious effects on cellular macromolecules, e.g., DNA, protein and lipids. However, more recent studies are showing that they are often utilized as signaling molecules and play an active part in regulating numerous cellular processes $^{[154]}$. An exquisitely regulated redox signaling is essential for various biological functions, including cell survival, cell growth, proliferation and differentiation, and immune response. Reduction and oxidation (redox) reactions play key roles as potent second messengers in cancer cells and are being targeted as novel cancer therapies ${ }^{[155]}$. However, it is also being increasingly realized that ROS and oxidative stress may have a dual role in cancer ${ }^{[156]}$. Oxidative stress can promote pro-tumorigenic signaling that increases cancer cell proliferation, survival, and adaptation to hypoxic microenvironments. On the other hand, regulated oxidative stress can also be used to promote antitumorigenic signaling and either trigger ROSinduced cancer cell apoptosis or suppress ROS-induced signaling that is essential for tumor cells. Indeed, redox reactions are able to activate signaling pathways such as mitogen activated-protein kinase (MAPK), extracellular-regulated kinase 1/2 (ERK1/2), phosphoinositide-3-kinase (PI3K), protein kinase B (AKT), and many more, which have been thoroughly reviewed by Zhang et al. ${ }^{[156]}$ (2016). Aggressive cancer cells take advantage of these altered redox signaling networks to facilitate their proliferation and invasion capabilities, and to acquire therapeutic resistance.

Increased oxidative stress and a decreased antioxidant capacity have been previously associated with aggressive prostate cancer ${ }^{[157]}$. Indeed, numerous recent findings also underscore the connection between 
oxidative stress and AR signaling, and the risk of developing CRPC tumors ${ }^{[158-160]}$. Shiota et al. ${ }^{[159]}$ (2010), had documented that Twist1, a member of basic helix-loop-helix transcription factors as well as AR was upregulated in response to hydrogen peroxide, and the response to which was abolished by an addition of N-acetyl cysteine (NAC) and Twist1 knockdown. In a more recent publication, this group also showed that gene polymorphisms in antioxidant enzymes correlate with the efficacy of ADT, clearly implicating the importance of oxidative stress with CRPC outgrowth ${ }^{[160]}$. In this respect, ligand-receptor interactions between androgens and AR is a major regulator of redox signaling in PCa cells ${ }^{[6,161-163]}$ and in dictating treatment resistance ${ }^{[162]}$. Therefore, it is now well accepted that sudden changes in androgen levels, such as during hormone deprivation, can drastically alter cellular homeostasis to increase oxidative stress, ROS production and dysregulated redox signaling networks. Fajardo et al. ${ }^{[163]},(2016)$ showed that exposure to an oxidation product of vitamin-E, $\alpha$-tocopherylquinone, decreased AR expression and protein levels. However, most interestingly, coexposure to the antioxidant form, a-tocopherol was able to abrogate this effect, suggesting that both oxidative stress and the resultant antioxidants are important in regulating AR function in androgen-responsive PCa cells. Studies have indicated that the modification of NOX expression by androgen may have significant implications on the response of PCa cells to hormone deprivation ${ }^{[161,164]}$ and a crucial role of both NOX4 and NOX5 has been suggested in CRPC cells by us ${ }^{[151]}$ and others ${ }^{[165,166]}$. Interestingly, a direct suppression of NOX-mediated ROS production showed significant suppression in cell proliferation and survival in PCa cells, whereas the quenching of ROS by using a GSH-mimetic was not as effective. Therefore, more potent strategies to abrogate the ADT-induced redox signaling network amplifications will be necessary to decrease CRPC selection and metastasis. Indeed, a crucial issue that is often overlooked is the role of sudden hormonal changes in facilitating the metastasis of CRPC cells, primarily to the bone marrow and brain ${ }^{[167,168]}$. Since androgen signaling plays an important role in normal physiology and cellular functions ${ }^{[169-172]}$, whole body hormone deprivation may result in systemic oxidative stress, especially in the bone marrow and brain, where the CRPC cells with an acquired redox-signaling network can find new sanctuaries and form metastatic foci, resulting in increased mortality associated with mCRPCs. Hence, potent compounds that may restore the antioxidant homeostasis in PCa patients following hormone deprivation, may not only suppress the selection of CRPC cells but may also decrease progression to metastatic CRPCs.

\section{NRF2 AS A THERAPEUTIC TARGET AGAINST CRPC PROGRESSION}

A constant high-level expression of the afore-mentioned antioxidant enzymes would be crucial to longterm protection from oxidative stress and compounds that augment their gene expression and protein levels may be of significant therapeutic value against CRPC progression. In this respect, the transcription factor nuclear factor erythroid 2-related factor $2\left(\mathrm{Nrf}_{2}\right)$ is known to be a master regulator of oxidative stress $^{[173,174]}$. Key findings in the field of chemoprevention has shown that the induction of Nrf2 may have significant potential in cancer. Studies in Nrf-2 knockout mice showed that the tumors generated in these mice are more aggressive and showed multiple organ metastasis ${ }^{[175]}$. Furthermore, the prevalence and size of colorectal cancers were increased in Nrf-2 knockout mice ${ }^{[176]}$. On the other hand, upregulation of Nrf-2 suppressed growth and migration of PCa cells by upregulating antioxidant proteins such as ferroportin ${ }^{[177]}$. However, despite the findings that oxidative stress is a potent stimulator of CRPC outgrowth (as discussed above) few studies have investigated the significance of Nrf2 signaling in CRPC cells and possible efficacy of activating the Nrf2 transcription factor to suppress CRPC progression.

In cooperation with $\mathrm{Nrf2}$, a number of related proteins such as Nrf1, Bach1, and the FoxO (forkhead box, class $\mathrm{O}$ ) family of transcription factors, especially $\mathrm{FoxO} 3$, are of significant importance in regulating the expression of the majority of antioxidant genes ${ }^{[178,179]}$. Together, these transcription factor families are responsible for ensuring that high levels of the antioxidant enzymes are produced to suppress the deleterious effects of oxidative stress and ROS. Therefore, strategies to activate these transcription factors, rather than the use of small molecule ROS quenching agents, e.g., GSH, n-acetyl cysteine (NAC), 
vitamin-E, vitamin-C, etc., may provide a more clinically applicable approach to suppress the amplified redox signaling that enables selection and progression of CRPC cells and their metastasis to sequestered sites.

Indeed, due to their potent effects, numerous recent studies are focusing on the regulation of transcriptional activity of Nrf2 in order to persistently suppress the deleterious effects of oxidative stress and the ROSinduced disease manifestations ${ }^{[152,180,181]}$. As explained in the previous sections, an integrated signaling network involving NF- $\kappa \mathrm{B}$ and AR plays a critical role in persistent AR signaling and the development of CRPC. The transcription factor Nrf- 2 is known to be a potent inhibitor of NF- $\kappa \mathrm{B}$ signaling, as evidenced with numerous phytochemicals and pharmaceuticals that have shown anticancer effects ${ }^{[22,182-184]}$. Furthermore, our recent findings demonstrated a direct role for Nrf2 in downregulating both AR expression and function ${ }^{[71,148,150-153]}$.

Briefly, Nrf2 belongs to the CNC-bZIP (cap'n'collar- basic leucine zipper) family of nuclear transcription factors ${ }^{[22,153,185]}$. In its inactive state, Nrf2 is usually bound to its cytoplasmic chaperone, Kelch-like ECHassociated protein 1 (Keap1) which dictates Nrf2's proteosomal degradation ${ }^{[174,181]}$. When cells are exposed to oxidative stress, Nrf2 dissociates from Keap1 and translocates to the nucleus. Within the nucleus, Nrf2 interacts with small Maf proteins, especially MafG, which are also bZIP-type transcription factors ${ }^{[186,187]}$. The Nrf2-MafG complex, along with other coactivators or corepressors, can regulate the transcription of numerous oxidative stress related genes by binding to their Electrophile Response Elements (EpRE) within promoter/enhancer regions of the $\mathrm{DNA}^{[188,189]}$. Nuclear localized $\mathrm{Nrf} 2$ and its binding to EpRE sequences can increase the expression of many antioxidant genes such as Prx-1, Txn-1, Gpx, HO-1, etc. Furthermore, EpRE like sequences have also been located in the promoter region of numerous other antioxidant genes including NQO1, glutathione S-transferaseA2 (GstA2), $\gamma$-glutamylcysteine synthetase (GCS), superoxide dismutase (SOD-1 and -2), ferritin and UDP-glucuronosyltransferase (UGT). Thus, a functional Nrf2 protein is essential for cell survival and several studies have shown that the knockdown of Nrf2 expression sensitizes cells to oxidative stress and apoptosis ${ }^{[190,191]}$. Interestingly, studies have also located several EpRE like sequences at close vicinity to the AR gene, which may regulate AR expression following oxidative stress and Nrf2 binding ${ }^{[151,192]}$. Findings indicate that the thioredoxin domain-containing 9 , an important regulator of ROS, can activate AR signaling ${ }^{[192]}$. Interestingly, in human prostate cancer cells, the NF- $\kappa \mathrm{B}$ inhibitor, curcumin and its potent analog ca27, were shown to down-regulate AR expression via an oxidative stress mediated mechanism ${ }^{[193]}$. Investigators showed that ROS production preceded AR loss and that ca27mediated down-regulation of the AR was decreased by the antioxidant, $\mathrm{N}$-acetyl cysteine.

Fluctuations in hormone levels may induce inflammation within tumor microenvironments and increase both $\mathrm{NF}_{-\kappa \mathrm{B}}$ and AR function, the extent of which can be potently regulated by nuclear Nrf2 levels. As discussed in the previous sections, following activation, both NF- $\mathrm{KB}$ and AR translocate into the nucleus and bind to their respective DNA response elements, leading to the expression of many genes associated with aggressive tumor growth and endocrine resistance. Oxidative stress leads to IкB kinase activation and phosphorylation of $I_{\kappa} B$, targeting it for polyubiquitination and proteasomal degradation, ultimately resulting in the release and nuclear translocation of NF- $\mathrm{KB}^{[14]}$. Similarly, AR is sequestered in the cytoplasm via several HSPs and translocates to the nucleus following its release due to ligand binding and dim erization $^{[20,52,54,79,81,98]}$. The same type of mechanism of Nrf2 nuclear translocation occurs due to ROSinduced inactivation of the Keap1 protein ${ }^{[173,174]}$. Nuclear translocated NF- $\kappa \mathrm{B}$ can directly inhibit Nrf-2 at the transcriptional level ${ }^{[194]}$ and vice vers ${ }^{[195]}$. In fact, NF- $\kappa \mathrm{B}$ was found to compete with $\mathrm{Nrf}-2$ for the transcriptional co-activator, CREB binding protein ${ }^{[195]}$. It was also reported that the physical association of the $\mathrm{N}$-terminal region of the p65 subunit of NF- $\mathrm{KB}$ with Keap1 can stabilize its association and inhibition of the Nrf-2 pathway ${ }^{[196]}$. This has significant implications on CRPC because NF- $\mathrm{KB}$ signaling is involved in PCa progression to androgen independence ${ }^{[197]}$. Furthermore, exposure to the Nrf2-activator, CDDO- 


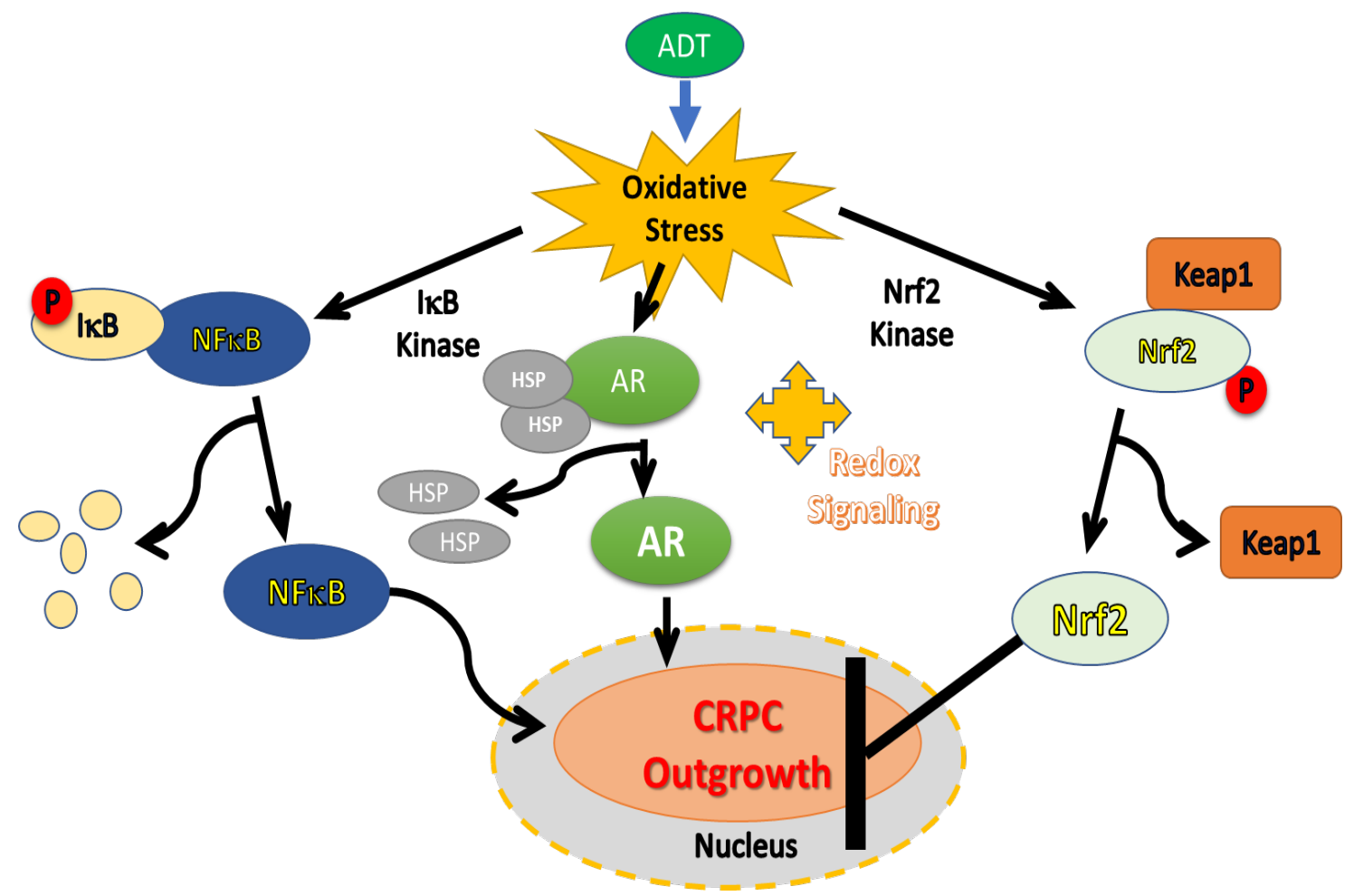

Figure 4. Crosstalk regulation of Nrf-2, NF- $\kappa B$ and AR signaling in CRPC cells. Hormone deprivation (ADT) induced oxidative stress and redox signaling activates both NF- $\mathrm{KB}$ and AR signaling that facilitates CRPC progression. Oxidative stress also increases Nrf2 nuclear levels which blocks both NF-кB and AR signaling. Thus, reduction of oxidative stress post-ADT by using potent Nrf2-activating agents may prevent CRPC outgrowth. CRPC: castrate resistant prostate cancer; NF- $\mathrm{B}$ : nuclear factor kappa B; AR: androgen receptor

me was shown to target HSPs, especially Hsp90 ${ }^{[198]}$. Crosstalk between Nrf-2, NF- $\kappa$ B and AR signaling may contribute to the transition of PCa cells to CRPC cells by persistent AR signaling, as depicted in Figure 4.

In the following sections, we have focused our attention on how the activation of Nrf2 may be used as a highly effective approach to suppress the amplified redox signaling networks that enable the constant activation of NF- $\kappa \mathrm{B}$ and AR signaling pathways in CRPC cells. We previously observed that Nrf-2 can decrease the transactivation function of $\mathrm{AR}^{[150]}$. Nrf-2 overexpression downregulated AR expression under basal conditions and decreased nuclear AR levels under DHT-stimulated conditions, and this effect was seen in both androgen-dependent (LNCaP) and androgen-independent (C4-2B) prostate cancer cell lines. Therefore, findings on several Nrf-2 activating agents are presented below.

\section{POTENTIAL OF CLINICALLY-TESTED NRF2-ACTIVATORS IN CRPC PATIENTS}

Due to the complexity of redox regulated pathways, attempts to augment antioxidant signaling via simple removal of ROS with small molecule antioxidants will not be sufficient because a network of antioxidant proteins, transcription factors, and ROS producing enzymes work together to maintain the ideal oxidative environment within aggressive PCa cells. Due to the mortality and morbidity associated with CRPC progression, therapeutic strategies that target ROS-induced AR signaling and androgen-independence would be of significant importance. Hence, there is a crucial need to identify promising Nrf2-activating agents that may abrogate CRPCs.

Since the pathogenic manifestations of most chronic diseases share common mechanisms, including oxidative, inflammation and metabolic alterations such as ER-stress and insulin resistance, the targeting 
of Nrf2 and Keap1 presents significant and lucrative potential ${ }^{[199,200]}$. At least 30 recent patents for Nrf2 modulators (up- or down-regulators) are indexed in the World International Property Organization. Although several potent Nrf2-activators have been discovered in the past, most of these are still in an early stage of development. However, these Nrf2-activators represent a first attempt to structure Nrf2 as a common therapeutic and systems medicine approach. In the following section, we will discuss a few of the most promising Nrf2 activating agents that are currently under different phases of clinical trials ${ }^{[200-204]}$. These include: (1) approved and repurposed agents, such as Dimethyl fumarate (DMF) and Oltipraz; (2) compounds isolated from natural sources, like curcumin, sulforaphane and resveratrol; and (3) highly potent triterpenoid derivatives, e.g., RTA 402, RTA-408 and CXA-10 [Table 2].

Although most of these compounds proved to be useful to some degree from a preclinical, proof-of-concept perspective, their clinical value to date has been generally very limited. Most of the potent Nrf2 activators are found to be electrophilic molecules that covalently modify, by oxidation or alkylation reactions, the cysteine residues present in the thiol-rich Keap1 protein. The majority of these Keap1 targeting agents are either repurposed agents, phytochemicals or pharmacological Nrf2 inducers.

\section{Repurposed agents}

Two previously approved drugs, dimethyl fumarate (DMF) and Oltipraz, are now being repurposed as potent anti-inflammatory agents due to their ability to increase Nrf2 nuclear localization at clinically achievable concentrations [Table 2]. Fumaric acid esters are known to be the most prominent examples of Keap1 modifiers. DMF is approved by the FDA for the treatment of psoriasis and multiple sclerosis (MS). Although it is not a cure for MS, it helps decrease the number of episodes and worsening MS symptoms by suppressing the acute inflammatory phase and chronic autoimmune dysfunction ${ }^{[205-208]}$.

Interestingly, Linker et al. ${ }^{[209]}$, (2011) had shown that parallel activation of both Nrf2-dependent and Nrf2independent mechanisms are associated with the therapeutic benefits of DMF. Indeed, DMF is a potent inhibitor of the NF- $\kappa \mathrm{B}$ transcription factor ${ }^{[210]}$ which enables it to rapidly decrease proinflammatory cytokines, adhesion molecules ${ }^{[211]}$ and neutrophil infiltration ${ }^{[212]}$. Clinical studies have demonstrated that DMF reduces inflammatory cytokines, inhibits the maturation of dendritic cells, and increases apoptosis of dendritic cells and T cells. Promising pre-clinical and clinical studies have also shown that the antioxidant effects of DMF facilitates the prevention of endothelial dysfunction in diabetes, atherosclerosis, kidney dysfunction, and other cardiovascular complications ${ }^{[213]}$.

Preclinical studies in tumor models have also shown significant antitumor activity of DMF, which has been linked to its ability to activate Nrf2 and inhibit the NF- $\kappa \mathrm{B}$ pathways ${ }^{[214,215]}$. Promising results have been observed with DMF in several types of cancer models such as glioblastoma, breast cancer, KRAS mutated cancers and myelogenous leukemia ${ }^{[216-219]}$. However, to our knowledge, the efficacy of DMF in prostate cancer patients, and especially, its ability to suppress CRPC progression has not been investigated so far. In light of our past findings on the suppressive effects of $\mathrm{Nrf2}$ on AR expression in PCa cells ${ }^{[150]}$, and the in vitro efficacy of $\mathrm{Nrf2}$-activators like sulforaphane ${ }^{[70,220]}$ and $\mathrm{CDDO}-\mathrm{me}^{[71]}$ in similarly suppressing $\mathrm{AR}$ and increasing the efficacy of antiandrogens (discussed later in this section), we believe that DMF, a relatively safe and well tolerated Nrf2 activator, should be tested as a suppressor of CRPC outgrowth in PCa patients undergoing ADT treatment.

Oltipraz is another repurposed agent under clinical trials due to its Nrf2 activating ability. Oltipraz is an organosulfur compound that has been used as an anti-schistosomal agent for a number of years ${ }^{[221]}$ and this compound is now being repurposed as an anti-inflammatory agent for liver diseases ${ }^{[222]}$. It is thought to manifest its therapeutic effects by inhibiting the inflammatory and oxidative stress induced pathologic progression of liver fibrosis ${ }^{[223]}$. Therefore, oltipraz is currently in several Phase-III trials for the treatment 
Table 2. The Nrf2 activators currently in multiple clinical trials

\begin{tabular}{lll}
\hline NRF2 activator & & Clinical trial \\
\hline CDDO-Me & Alport syndrome & Phase III \\
(RTA-402) & Chronic kidney disease & Phase III \\
& Diabetic nephropathy & Phase III \\
& Liver disease & Phase II \\
CDDO-DFPA & Pulmonary hypertension & Phase III \\
(RTA-408) & Mitochondrial myopathy & Phase II \\
& Melanoma & Phase II \\
Curcumin & Breast cancer & Phase II \\
& Type 2 Diabetes mellitus & Phase IV \\
& Chronic kidney disease & Phase III \\
CXA-10 & Neoplasm & Phase II \\
Dimethyl fumarate & Prostate cancer & Phase III \\
(DMF) & Acute kidney injury & Phase I \\
& Multiple sclerosis & Approved \\
& Psoriasis & Approved \\
& Rheumatoid arthritis & Phase II \\
Oltipraz & Cutaneous T cell lymphoma & Phase II \\
Resveratrol & Chronic lymphocytic leukemia small lymphocytic lymphoma & Phase I \\
& NASH & Phase III \\
Sulforaphane & Type 2 diabetes mellitus & Phase I \\
& Endometriosis & Phase IV \\
\hline & Colorectal cancer & Phase I \\
& Prostate cancer & Phase II
\end{tabular}

of nonalcoholic steatohepatitis (NASH). Due to its xenobiotic effects on liver enzymes (Cyp450), the Nrf2mediated antioxidant effects of Oltipraz has also shown significant liver accumulation and promise in the treatment of NASH. However, there has been little evidence that this approved drug may be effectively repositioned for cancer treatment, primarily due to the side-effects and drug-drug interaction issues associated with high dose oltipraz use ${ }^{[224]}$. Since both the pharmacokinetics and pharmacodynamics of this drug are well established, it may be beneficial to investigate whether oltipraz has any suppressive effect on $\mathrm{AR}$ and NF- $\mathrm{B}$ function in PCa cells and whether it may suppress CRPC progression.

\section{Natural compounds}

Because of their time-tested safety and efficacy, a huge number of natural product-derived antioxidant compounds, which are known to increase $\mathrm{Nrf} 2$, are currently in various stages of clinical development. The potent Nrf2 inducing and NF- $\mathrm{B}$ inhibitory effects of phytochemicals like curcumin, sulforaphane and resveratrol are currently in several late-stage clinical trials for a variety of different inflammation and oxidative stress [Table 2].

Curcumin, the active component of Curcuma longa (the Indian spice turmeric), has shown significant promise as a potent antioxidant and is in several late-stage clinical trials. Curcumin's antioxidant properties are being investigated in the treatment of obesity, metabolic syndrome, and prediabetes. In vivo studies have clearly shown that curcumin intake decreases inflammation and protects the liver by upregulating $\mathrm{Nrf2}^{[225]}$. Several drug-development studies have indicated that the oral intake of curcumin reduces serum triglycerides, IL-1 $\beta$, IL-4, and VEGF and increases lipoprotein lipases that are helpful in breaking down fat ${ }^{[226,227]}$. With respect to cancer, the well-known anti-inflammatory and anti-cancer properties, and the multimodal actions of this phytochemical, prompted a number of laboratories to investigate the utility of curcumin as an adjunct to chemotherapy ${ }^{[228]}$. In addition to its potent effects in suppressing 
NF- $\mathrm{KB}$ activation, curcumin can also inhibit the PI3K/Akt pathway and induce ER-stress in cancer cells $^{[229,230]}$. In colon cancer cells, curcumin has also been shown to trigger cell death by increasing stressinduced autophagy ${ }^{[231]}$. In lung cancer cells, curcumin exhibited synergistic effects when combined with docetaxel $^{[232]}$. Studies have also documented the therapeutic benefit of curcumin against aggressive PCa and CRPC progression, both in vitro and in vivo ${ }^{[233-235]}$. Our past publication also showed the in vitro chemosensitizing effects of curcumin in PCa cells, especially when combined with another stress-inducing agent, the approved anti-HIV drug nelfinavir ${ }^{[236]}$. In CRPC cells, similar to our findings, several other groups have also documented that exposure to curcumin can suppress both AR expression and activity and increase the efficacy of antiandrogens. Interestingly, this effect was not only observed in prostate cancer cells $^{[233,237,238]}$ but also in endocrine resistant (triple negative) breast cancer cells that express AR protein ${ }^{[239]}$. However, these therapeutic effects of curcumin were evident only at high concentrations $(\geq 10 \mu \mathrm{mol} / \mathrm{L})$, which is difficult to achieve in vivo ${ }^{[234,240]}$. Hence, numerous pharmaceutical companies are trying to develop more potent curcumin analogs, e.g., ASC-J9 or dimethylcurcumin ${ }^{[241]}$ and liposomal formulations of curcumin, to increase its bioavailability ${ }^{[242]}$. As early as 2012, Yamashita et al ${ }^{[243]},(2012)$ had shown that ASC-J9 suppresses CRPC growth through the degradation of both full-length and splice variants of AR. However, a direct mechanistic link to the role of oxidative stress and the targeting of NF- $\kappa \mathrm{B}$ or the Nrf2 pathways by ASC-J9 was not postulated in this manuscript. As documented above, the crosstalk between $\mathrm{AR}$ and NF- $\mathrm{KB}$ transcription factors is crucial for augmenting CRPC progression, where the suppressive effects of this Nrf2-activating phytochemical may be a promising candidate in abrogating endocrine resistance in PCa patients.

Another promising natural Nrf2 activating compound is sulforaphane, an isothiocyanate chemical present in cruciferous vegetables, such as broccoli ${ }^{[24]}$. Similar to curcumin, the mechanism primarily responsible for sulforaphane's action was found to be potent suppression of both NF-кB DNA binding and transcriptional activation of the NF- $\mathrm{KB}$ regulated genes, apparently by modulating intracellular redox conditions ${ }^{[245]}$. Therefore, this natural compound is in several clinical trials to treat numerous inflammation-associated chronic diseases including cancer, asthma, chronic kidney disease, type 2 diabetes mellitus, and schizophrenia ${ }^{[224,246,247]}$. In type 2 diabetes mellitus, sulforaphane decreased gluconeogenesis and helped achieve glycemic control by increasing nuclear translocation of $\mathrm{Nrf}_{2}{ }^{[248]}$. Sulforaphane also reduced cardiovascular risk by decreasing serum triglycerides, and inflammatory markers including C-reactive protein and IL-6. Interestingly, studies have shown that SFN may also induce Nrf2 by decreasing TGF- $\beta$ and JAK/STAT signaling ${ }^{[249,250]}$. In the kidney, sulforaphane protects renal cells by decreasing ROS and inhibiting both NF- $\kappa$ B and TGF- $\beta$ signaling ${ }^{[251]}$.

Sulforaphane has been tested for both its chemopreventive ${ }^{[252,253]}$ and anticancer ${ }^{[254]}$ effects. Similar to curcumin, two of the most critical pathways by which sulforaphane displays its potent effect in PCa cells are Nrf2 activation and NF- $\kappa \mathrm{B}$ inhibition. Furthermore, exposure to purified sulforaphane decreased proliferation in TRAMPC1 PCa cells in vitro ${ }^{[255]}$ and a diet rich in broccoli sprouts augmented Nrf2 expression and suppressed tumor development in the TRAMP (transgenic adenocarcinoma of mouse prostate) mouse model ${ }^{[256]}$. The reduction in tumor growth was reported to be linked with the stimulation of both Nrf2 and HO-1 proteins and inhibition of the Keap1 protein ${ }^{[257]}$. Furthermore, we recently showed that exposure to sulforaphane decreases AR levels and increases the efficacy of anti-androgens in PCa cell $^{[70]}$. Most importantly, this hormone sensitizing efficacy of sulforaphane was also documented in the CRPC cell line, CWR22Rv1, further underscoring the therapeutic potential of Nrf2 activators.

A third phytochemical, which is produced by plants in response to injury or pathogens, is also showing promise as a safe $\mathrm{Nrf2}$-activating agent ${ }^{[258]}$. Resveratrol is a stilbenoid, a type of natural phenol, and is found in high quantities in the skin of grapes, blueberries, raspberries, mulberries, and peanuts. Due to its favorable and safe pharmacokinetics profile, resveratrol is in several late-stage clinical trials ${ }^{[259]}$. Indeed, 
resveratrol prevents cardiovascular, inflammatory, and metabolic complications in hypertension, diabetes, heart disease, and atherosclerosis ${ }^{[260]}$. It decreases inflammatory markers including IL-1 $\beta$ and TNF- $\alpha$ by the downregulation of Keap 1 expression, leading to the activation of Nrf2 signaling ${ }^{[261,262]}$. Resveratrol is also showing significant promise as an anti-cancer agent, against breast ${ }^{[263]}$, colorectal $^{[264]}$ and prostate cancers $^{[265]}$; however, most of these studies have been directed towards its chemopreventive effects and not as a therapeutic against endocrine resistance. Resveratrol was found to enhance the degradation of both $\mathrm{AR}$ and AR-V7 in prostate cancer cells ${ }^{[266]}$. Interestingly, in a recent study by De Amicis et al. ${ }^{[267]}$, (2019), resveratrol's anticancer effects in both breast and prostate cancer cells was found to be the targeting of steroid hormone receptor signaling. Therefore, the above findings highlight the existing viability and significance of the use of natural products as sources of new candidate Nrf2-activator drugs to test in PCa patients undergoing hormone deprivation therapy.

\section{Triterpenoid derivatives}

Synthetic triterpenoids are very potent Nrf2 activators and are effective even at nanomolar concentrations ${ }^{[181,268]}$. These are derivatives of 2-cyano3,12-dioxo-oleana-1,9(11)-dien-28-oate (CDDO; bardoxolone, RTA-401) that resemble the natural product oleanolic acid. In fact, the derivative CDDOmethyl ester (CDDO-Me, RTA-402) was first chosen to be in clinical trials for the treatment of diabetic nephropathy ${ }^{[269]}$. However, it had to be discontinued due to the risks associated with cardiovascular complications ${ }^{[270]}$. Currently, because of its potency and favorable in vivo pharmacokinetics ${ }^{[271]}$, CDDOMe is currently under clinical investigation for potential treatment in Alport syndrome and pulmonary hypertension ${ }^{[272]}$. Indeed, CDDO-Me is one of the most well-studied synthetic triterpenoids showing potent anticarcinogenic activities ${ }^{[273]}$. Studies with CDDO-Me have been conducted in various kinds of cancers such as prostate ${ }^{[274]}$, breast ${ }^{[275]}$, ovary ${ }^{[276]}$, lung ${ }^{[277]}$, pancreatic ${ }^{[278]}$, and osteosarcoma ${ }^{[279]}$. Most importantly, unlike the phytochemical Nrf2 activators, CDDO-me has been shown to be effective at low nanomolar concentrations. At these physiologically achievable concentrations, CDDO-me was shown to reduce intracellular ROS levels via the transcriptional induction of numerous antioxidant proteins, e.g., SOD and Gpx, leading to a synchronized antioxidant and anti-inflammatory response ${ }^{[280]}$. In vivo studies have reported potent inhibitory effects of CDDO-Me on tumor growth, metastasis and angiogenesis and has demonstrated promising anticancer effects in Phase I clinical trials against advanced solid tumors and lymphomas ${ }^{[281]}$. However, although multiple studies with CDDO-Me have been conducted using PCa cells $^{[274,282,283]}$, its efficacy to suppress CRPC progression has not been thoroughly investigated. In our recently published investigations, we documented that CDDO-Me suppresses both gene expression and protein levels of full-length AR and AR variants ${ }^{[7]}$. Furthermore, co-treatment with physiologically achievable doses of CDDO-Me was able to sensitize PCa cells to the cytotoxic effects of a clinically approved antiandrogenic drug, enzalutamide. These findings implicate the potential of CDDO-Me as an adjunct therapy to ADT in patients with CRPC tumors, especially those overexpressing AR and demonstrate a constitutive AR function. Due to the significant morbidity and mortality associated with CRPC progression and the crucial role of oxidative stress and NF- $\mathrm{BB}$, it is imperative that this potent Nrf2-activating agent be initiated in a clinical trial to document its safety and efficacy in PCa patients undergoing hormone deprivation.

A number of laboratories are trying to synthesize safer and more potent triterpenoid derivatives with possible clinical applications as anti-inflammatory agents due to their Nrf2 activating potential. Another CDDO derivative, CDDO-difluoropropionamide (RTA-408, Omaveloxolone) with a better safety profile, is currently under clinical trials for myopathy ${ }^{[284]}$. Indeed, this newly synthesized triterpenoid has been shown to have a broad anticancer and anti-inflammatory activity ${ }^{[285]}$. Due to its effects in suppressing oxidative stress, omaveloxolone has been used in Friedreich's ataxia models to suppress mitochondrial defects ${ }^{[286]}$ and to increase the regenerative capacity of diabetic wounds ${ }^{[287]}$. By suppressing chronic inflammation and immune dysfunction, this Nrf2 activator has also been shown to attenuate osteoclast production ${ }^{[288]}$ and nonalcoholic steatohepatitis (NASH) ${ }^{[289]}$. A third oleic acid derivative currently under early stage clinical 
trial is 10-nitro oleic acid (NO2-OA) or CXA-10 ${ }^{[290]}$. Because of its enhanced bioavailability, this new Nrf2-activating compound is in trials for the potential treatment of acute kidney injury ${ }^{[291]}$. In light of the crucial role of inflammatory mechanisms that are activated in PCa cells undergoing hormone deprivation, therapeutic strategies that may suppress the vicious cycle of redox signaling that enable the selection and outgrowth of CRPC tumors need to be developed soon. The above mentioned Nrf2 activators, which are at different stages of clinical trials and have been shown to be relatively safe under chronic treatment settings, may have profound therapeutic value as an adjunct therapy in patients undergoing ADT.

There are several important caveats that need to be addressed towards the possible use of potent antioxidants such as Nrf2 activators towards the suppression of CRPC outgrowth post-ADT. It should be noted that Nrf2 plays a dual role in both cancer initiation and progression, and in dictating the efficacy of anticancer agents. During the early stages, Nrf2 has a protective role with respect to cancer development by inactivating the ROS-induced mutagenic effects of carcinogens. Indeed, the loss of Nrf2 function can promote neoplastic transformation of primary cells ${ }^{[149,152]}$. However, once tumors have developed, the activation of Nrf2 may protect tumor cells from ROS-mediated cytotoxicity, which is essential for the success of both radiotherapy and chemotherapy ${ }^{[292]}$. On the contrary, the acquisition of hormone resistance in PCa cells may be suppressed by exploiting the potent antioxidant effects of Nrf2-activating agents. Indeed, Nrf2 expression is often downregulated in CRPC cells ${ }^{[15,64]}$. Thus, chemo/radio-resistance and ADT resistance may be due to the opposing effects of Nrf2, which underscore the crucial importance of careful evaluation during the clinical application of Nrf2-activators in patients with early stage PCa. Furthermore, since a gradual adaptation to oxidative stress occurs during the acquisition of resistance to both chemotherapy and radiotherapy, the utility of Nrf2-activators in suppressing the development of endocrine resistance may need to be understood properly prior to their use as an adjunct to ADT. In this respect, a recent study by Ciamporcero et al. ${ }^{[293]}$ (2018) showed that crosstalk between Nrf2 and YAP transcription factors help maintain the antioxidant capacity of bladder cancer cells, which facilitate their acquisition of chemoresistance. Therefore, the therapeutic potential Nrf2 activation strategies to suppress CRPC outgrowth post-ADT will need to be directed towards the blockade of novel AR-independent mitogenic signaling networks in PCa cells.

For decades, different strategies to suppress the crucial AR-mediated mitogenic signaling in PCa cells have been the treatment of choice in $\mathrm{ADT}^{[33,38,46]}$. In addition to suppressing the sources of androgens, combination therapy with antiandrogens has been used to suppress AR signaling more fully. In recent years, alternate strategies to suppress AR protein levels in PCa cells by using inhibitors of AR chaperones (Hsp70, Hsp90), which increases AR degradation via the proteasomes, have shown some promise ${ }^{[294,295]}$. Several bromodomain inhibitors that prevent protein-protein interactions between the BET proteins, acetylated histones, and the AR transcription factor, are also being tested for CRPC patients ${ }^{[296,297]}$. Attempts to suppress the crosstalk between AR and IL- 6 signaling using monoclonal antibodies against IL- 6 or IL- 6 receptors are also being investigated in order to decrease CRPC development ${ }^{[105,130]}$. With new evidence that CRPC cells may need a simultaneous suppression of multiple redox regulated signaling mechanisms, the therapeutic potential of Nrf-2 activators in PCa cells undergoing hormone deprivation needs to be understood. Combination therapy with these AR suppressive mechanisms may be used as an adjunct to $\mathrm{ADT}$ to abrogate endocrine resistance in prostate cancer.

\section{CONCLUSION}

Numerous past studies have suggested that hormone-deprivation induced oxidative stress and redox signaling in PCa cells can lead to the selection of cells with a CRPC phenotype. An inflammatory tumor microenvironment, which occurs due to the increased synthesis and secretion of multiple cytokines and chemokines by the tumor cells, and both tumor-associated stromal cells and macrophages, may amplify the second messenger signaling in the surviving PCa cells. Findings from numerous studies suggest that 


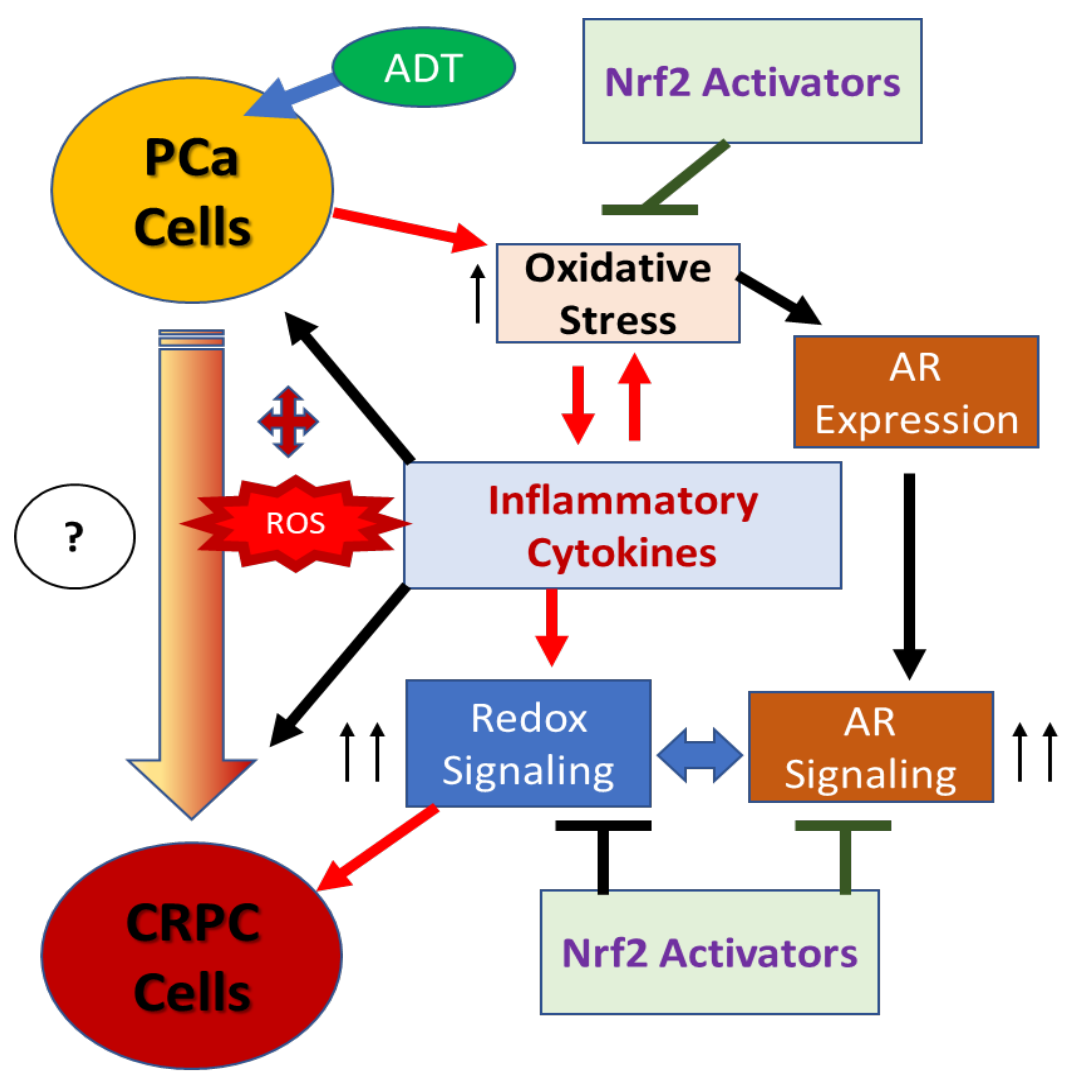

Visual Abstract

Figure 5. Therapeutic potential of Nrf2 activators in suppressing ADT-induced oxidative stress and CRPC progression. Androgen deprivation increases oxidative stress in PCa cells, which causes inflammation and redox signaling amplification in surviving tumor cells. This vicious cycle of signaling crosstalk between AR and non-AR signaling pathways facilitates the selection and outgrowth of CRPC. Potent Nrf2 activators, especially those under clinical trials, may abrogate this vicious cycle and suppress the development of endocrine resistant PCa. CRPC: castrate resistant prostate cancer; AR: androgen receptor; ADT: androgen deprivation therapy

ADT-induced oxidative stress enables both the tumor cells and the tumor microenvironment to express inflammatory cytokines, which may further amplify the levels of ROS generation and enable a vicious cycle of signaling crosstalk with AR and non-AR signaling, resulting in the outgrowth of endocrine resistance. Therefore, mechanisms that regulate the pro- and anti-oxidant activities in PCa cells undergoing hormone deprivation, as well as therapeutic strategies that may be used to suppress this vicious cycle, may be an effective strategy to suppress CRPC progression [Figure 5]. In this respect, the regulation of redox signaling and antioxidant gene expression by the Nrf2 transcription factor may have multiple effects on abrogating the endocrine resistant phenotype of PCa. An integrated signaling network involving NF- $\kappa \mathrm{B}$ and AR plays a critical role in persistent AR signaling and the development of CRPC, where potent Nrf2 activators, especially those under clinical trials for numerous other ailments, may be of significant therapeutic value [Figure 5].

\section{DECLARATIONS}

\section{Authors' contributions}

Conceived: Mondal D

Designed: Mondal D

Written, reviewed, discussed, edited, and revised: Mondal D, Narwani D, Notta S, Ghaffar D, Mardhekar N, Quadri SSA 


\section{Availability of data and materials}

Not applicable.

\section{Financial support and sponsorship}

This work was supported by an intramural research grant from (LMU-DCOM) to Mondal D and Quadri SSA.

\section{Conflicts of interest}

All authors declared that there are no conflicts of interest.

\section{Ethical approval and consent to participate}

Not applicable.

\section{Consent for publication}

Not applicable.

\section{Copyright}

(c) The Author(s) 2021.

\section{REFERENCES}

1. Rawla P. Epidemiology of prostate cancer. World J Oncol 2019;10:63-89.

2. Das H, Rodriguez R. Health care disparities in urologic oncology: a systematic review. Urology 2020;136:9-18.

3. Chen R, Ren S; Chinese Prostate Cancer Consortium, et al. Prostate cancer in Asia: a collaborative report. Asian J Urol 2014;1:15-29.

4. Ha Chung B, Horie S, Chiong E. The incidence, mortality, and risk factors of prostate cancer in Asian men. Prostate Int 2019;7:1-8.

5. Labbé DP, Zadra G, Ebot EM, et al. Role of diet in prostate cancer: the epigenetic link. Oncogene 2015;34:4683-91.

6. Kgatle MM, Kalla AA, Islam MM, Sathekge M, Moorad R. Prostate cancer: epigenetic alterations, risk factors, and therapy. Prostate Cancer 2016;2016:5653862.

7. Costa-Pinheiro P, Patel HR, Henrique R, Jerónimo C. Biomarkers and personalized risk stratification for patients with clinically localized prostate cancer. Expert Rev Anticancer Ther 2014;14:1349-58.

8. Udensi UK, Tchounwou PB. Oxidative stress in prostate hyperplasia and carcinogenesis. J Exp Clin Cancer Res 2016;35:139.

9. Yu YD, Byun SS, Lee SE, Hong SK. Impact of body mass index on oncological outcomes of prostate cancer patients after radical prostatectomy. Sci Rep 2018;8:11962.

10. Parikesit D, Mochtar CA, Umbas R, Hamid AR. The impact of obesity towards prostate diseases. Prostate Int 2016;4:1-6.

11. Harijith A, Ebenezer DL, Natarajan V. Reactive oxygen species at the crossroads of inflammasome and inflammation. Front Physiol 2014;5:352.

12. Khandrika L, Kumar B, Koul S, Maroni P, Koul HK. Oxidative stress in prostate cancer. Cancer Lett 2009;282:125-36.

13. Landskron G, De la Fuente M, Thuwajit P, Thuwajit C, Hermoso MA. Chronic inflammation and cytokines in the tumor microenvironment. J Immunol Res 2014;2014:149185.

14. Taniguchi K, Karin M. NF-кB, inflammation, immunity and cancer: coming of age. Nat Rev Immunol 2018;18:309-24.

15. Karantanos T, Corn PG, Thompson TC. Prostate cancer progression after androgen deprivation therapy: mechanisms of castrate resistance and novel therapeutic approaches. Oncogene 2013;32:5501-11.

16. Hoang DT, Iczkowski KA, Kilari D, See W, Nevalainen MT. Androgen receptor-dependent and -independent mechanisms driving prostate cancer progression: opportunities for therapeutic targeting from multiple angles. Oncotarget 2017;8:3724-45.

17. Huang Y, Jiang X, Liang X, Jiang G. Molecular and cellular mechanisms of castration resistant prostate cancer. Oncol Lett 2018;15:606376.

18. DiNatale A, Fatatis A. The bone microenvironment in prostate cancer metastasis. Adv Exp Med Biol 2019;1210:171-84.

19. Dong L, Zieren RC, Xue W, de Reijke TM, Pienta KJ. Metastatic prostate cancer remains incurable, why? Asian J Urol 2019;6:26-41.

20. Hu R, Denmeade SR, Luo J. Molecular processes leading to aberrant androgen receptor signaling and castration resistance in prostate cancer. Expert Rev Endocrinol Metab 2010;5:753-64.

21. Azevedo A, Cunha V, Teixeira AL, Medeiros R. IL-6/IL-6R as a potential key signaling pathway in prostate cancer development. World $J$ Clin Oncol 2011;2:384-96.

22. Wardyn JD, Ponsford AH, Sanderson CM. Dissecting molecular crosstalk between Nrf2 and NF-kB response pathways. Biochem Soc Trans 2015;43:621-6.

23. Wilson AH. The prostate gland: a review of its anatomy, pathology, and treatment. JAMA 2014;312:562.

24. Litwin MS, Tan HJ. The diagnosis and treatment of prostate cancer: a review. JAMA 2017;317:2532-42. 
25. Ilic D, Djulbegovic M, Jung JH, et al. Prostate cancer screening with prostate-specific antigen (PSA) test: a systematic review and metaanalysis. BMJ 2018;362:k3519.

26. Wu JT. Assay for prostate specific antigen (PSA): problems and possible solutions. J Clin Lab Anal 1994;8:51-62.

27. Descotes JL. Diagnosis of prostate cancer. Asian J Urol 2019;6:129-36.

28. Oranusi CK, Ugezu AI, Nwofor A. Diagnosis of prostate cancer with needle biopsy: should all cases be biopsied before treatment? Niger J Clin Pract 2012;15:48-50.

29. Chang AJ, Autio KA, Roach M 3rd, Scher HI. High-risk prostate cancer-classification and therapy. Nat Rev Clin Oncol 2014;11:308-23.

30. Grignon DJ. Prostate cancer reporting and staging: needle biopsy and radical prostatectomy specimens. Mod Pathol 2018;31:S96-109.

31. Barakzai MA. Prostatic adenocarcinoma: a grading from gleason to the new grade-group system: a historical and critical review. Asian Pac J Cancer Prev 2019;20:661-6.

32. Alford AV, Brito JM, Yadav KK, Yadav SS, Tewari AK, Renzulli J. The use of biomarkers in prostate cancer screening and treatment. Rev Urol 2017;19:221-34.

33. Isbarn H, Boccon-Gibod L, Carroll PR, et al. Androgen deprivation therapy for the treatment of prostate cancer: consider both benefits and risks. Eur Urol 2009;55:62-75.

34. Liu F, Sun D, Zhou X, et al. Effect of adjuvant hormone therapy in patients with prostate cancer: a meta-analysis of randomized controlled trials. Medicine (Baltimore) 2018;97:e13145.

35. Xu X, Chen X, Hu H, Dailey AB, Taylor BD. Current opinion on the role of testosterone in the development of prostate cancer: a dynamic model. BMC Cancer 2015;15:806.

36. Balk SP. Androgen receptor functions in prostate cancer development and progression. Asian J Androl 2014;16:561-4.

37. Agoulnik IU, Weigel NL. Androgen receptor action in hormone-dependent and recurrent prostate cancer. J Cell Biochem 2006;99:362-72.

38. Perlmutter MA, Lepor H. Androgen deprivation therapy in the treatment of advanced prostate cancer. Rev Urol 2007;9 Suppl 1(Suppl 1):S3-8.

39. Kunath F, Grobe HR, Rücker G, et al. Non-steroidal antiandrogen monotherapy compared with luteinising hormone-releasing hormone agonists or surgical castration monotherapy for advanced prostate cancer. Cochrane Database Syst Rev 2014;(6):CD009266.

40. Kunath F, Jensen K, Pinart M, et al. Early versus deferred standard androgen suppression therapy for advanced hormone-sensitive prostate cancer. Cochrane Database Syst Rev 2019;6:CD003506.

41. Weiner AB, Cohen JE, DeLancey JO, Schaeffer EM, Auffenberg GB. Surgical versus medical castration for metastatic prostate cancer: use and overall survival in a national cohort. J Urol 2020;203:933-9.

42. Lian F, Sharma NV, Moran JD, Moreno CS. The biology of castration-resistant prostate cancer. Curr Probl Cancer 2015;39:17-28.

43. Scott LJ. Enzalutamide: a review in castration-resistant prostate cancer. Drugs 2018;78:1913-24.

44. Iguchi T, Tamada S, Kato M, Yasuda S, Yamasaki T, Nakatani T. Enzalutamide versus flutamide for castration-resistant prostate cancer after combined androgen blockade therapy with bicalutamide: study protocol for a multicenter randomized phase II trial (the OCUUCRPC study). BMC Cancer 2019;19:339.

45. Evans CP, Higano CS, Keane T, et al. The PREVAIL study: primary outcomes by site and extent of baseline disease for enzalutamidetreated men with chemotherapy-naïve metastatic castration-resistant prostate cancer. Eur Urol 2016;70:675-83.

46. Lei JH, Liu LR, Wei Q, et al. Androgen-deprivation therapy alone versus combined with radiation therapy or chemotherapy for nonlocalized prostate cancer: a systematic review and meta-analysis. Asian J Androl 2016;18:102-7.

47. Buonerba C, Sonpavde G, Vitrone F, et al. The influence of prednisone on the efficacy of cabazitaxel in men with metastatic castrationresistant prostate cancer. $J$ Cancer 2017;8:2663-8.

48. Den RB, George D, Pieczonka C, McNamara M. Ra-223 treatment for bone metastases in castrate-resistant prostate cancer: practical management issues for patient selection. Am J Clin Oncol 2019;42:399-406.

49. Marshall CH, Park JC, DeWeese TL, et al. Randomized phase II study of sipuleucel-T (SipT) with or without radium-223 (Ra223) in men with asymptomatic bone-metastatic castrate-resistant prostate cancer (mCRPC). Abstract 130. Presented at: ASCO Annual Genitourinary Cancers Symposium; February 13-15, 2020. San Francisco, CA; 2020.

50. Davey RA, Grossmann M. Androgen receptor structure, function and biology: from bench to bedside. Clin Biochem Rev 2016;37:3-15.

51. Fujita K, Nonomura N. Role of androgen receptor in prostate cancer: a review. World J Mens Health 2019;37:288-95.

52. Nyquist MD, Dehm SM. Interplay between genomic alterations and androgen receptor signaling during prostate cancer development and progression. Horm Cancer 2013;4:61-9.

53. Augello MA, Den RB, Knudsen KE. AR function in promoting metastatic prostate cancer. Cancer Metastasis Rev 2014;33:399-411.

54. Eftekharzadeh B, Banduseela VC, Chiesa G, et al. Hsp70 and Hsp40 inhibit an inter-domain interaction necessary for transcriptional activity in the androgen receptor. Nat Commun 2019;10:3562.

55. Koochekpour S. Androgen receptor signaling and mutations in prostate cancer. Asian J Androl 2010;12:639-57.

56. Sharma NL, Massie CE, Ramos-Montoya A, et al. The androgen receptor induces a distinct transcriptional program in castration-resistant prostate cancer in man. Cancer Cell 2013;23:35-47.

57. Gritsina G, Gao WQ, Yu J. Transcriptional repression by androgen receptor: roles in castration-resistant prostate cancer. Asian J Androl 2019;21:215-23.

58. Wirth MP, Hakenberg OW, Froehner M. Antiandrogens in the treatment of prostate cancer. Eur Urol 2007;51:306-14.

59. Culig Z. Androgen receptor coactivators in regulation of growth and differentiation in prostate cancer. J Cell Physiol 2016;231:270-4.

60. Muramatsu K, Matsui H, Sekine Y, et al. Androgen receptor coactivator p120 subtype $\beta$ is highly expressed in prostate cancer. Prostate Int 2013;1:10-5. 
61. Lopez SM, Agoulnik AI, Zhang M, et al. Nuclear receptor corepressor 1 expression and output declines with prostate cancer progression. Clin Cancer Res 2016;22:3937-49.

62. Varenhorst E, Klaff R, Berglund A, Hedlund PO, Sandblom G; Scandinavian Prostate Cancer Group (SPCG) Trial No. 5. Predictors of early androgen deprivation treatment failure in prostate cancer with bone metastases. Cancer Med 2016;5:407-14.

63. Jackson WC, Schipper MJ, Johnson SB, et al. Duration of androgen deprivation therapy influences outcomes for patients receiving radiation therapy following radical prostatectomy. Eur Urol 2016;69:50-7.

64. Chandrasekar T, Yang JC, Gao AC, Evans CP. Mechanisms of resistance in castration-resistant prostate cancer (CRPC). Transl Androl Urol 2015;4:365-80.

65. Song B, Park SH, Zhao JC, et al. Targeting FOXA1-mediated repression of TGF- $\beta$ signaling suppresses castration-resistant prostate cancer progression. J Clin Invest 2019;129:569-82.

66. Wasmuth EV, Hoover EA, Antar A, Klinge S, Chen Y, Sawyers CL. Modulation of androgen receptor DNA binding activity through direct interaction with the ETS transcription factor ERG. Proc Natl Acad Sci U S A 2020;117:8584-92.

67. Zhang X, Morrissey C, Sun S, et al. Androgen receptor variants occur frequently in castration resistant prostate cancer metastases. PLoS One 2011;6:e27970.

68. Wang Z, Shen H, Liang Z, Mao Y, Wang C, Xie L. The characteristics of androgen receptor splice variant 7 in the treatment of hormonal sensitive prostate cancer: a systematic review and meta-analysis. Cancer Cell Int 2020;20:149.

69. Reddy V, Iskander A, Hwang C, et al. Castration-resistant prostate cancer: androgen receptor inactivation induces telomere DNA damage, and damage response inhibition leads to cell death. PLoS One 2019;14:e211090.

70. Khurana N, Kim H, Chandra PK, et al. Multimodal actions of the phytochemical sulforaphane suppress both AR and AR-V7 in $22 \mathrm{Rv} 1$ cells: advocating a potent pharmaceutical combination against castration-resistant prostate cancer. Oncol Rep 2017;38:2774-86.

71. Khurana N, Chandra PK, Kim H, Abdel-Mageed AB, Mondal D, Sikka SC. Bardoxolone-methyl (CDDO-Me) suppresses androgen receptor and its splice-variant AR-V7 and enhances efficacy of enzalutamide in prostate cancer cells. Antioxidants (Basel) 2020;9:68.

72. Hodgson MC, Bowden WA, Agoulnik IU. Androgen receptor footprint on the way to prostate cancer progression. World J Urol 2012;30:279-85.

73. Bastos DA, Antonarakis ES. CTC-derived AR-V7 detection as a prognostic and predictive biomarker in advanced prostate cancer. Expert Rev Mol Diagn 2018;18:155-63.

74. Bennett HL, Stockley J, Fleming JT, et al. Does androgen-ablation therapy (AAT) associated autophagy have a pro-survival effect in LNCaP human prostate cancer cells? BJU Int 2013;111:672-82.

75. Das TP, Suman S, Alatassi H, Ankem MK, Damodaran C. Inhibition of AKT promotes FOXO3a-dependent apoptosis in prostate cancer. Cell Death Dis 2016;7:e2111.

76. Wolf P. Tumor-specific induction of the intrinsic apoptotic pathway-a new therapeutic option for advanced prostate cancer? Front Oncol 2019;9:590.

77. Wang X, Wen J, Li R, Qiu G, Zhou L, Wen X. Gene expression profiling analysis of castration-resistant prostate cancer. Med Sci Monit 2015;21:205-12.

78. Josefsson A, Larsson K, Freyhult E, Damber JE, Welén K. Gene expression alterations during development of castration-resistant prostate cancer are detected in circulating tumor cells. Cancers (Basel) 2019;12:39.

79. Schweizer MT, Yu EY. Persistent androgen receptor addiction in castration-resistant prostate cancer. J Hematol Oncol 2015;8:128.

80. Chang KH, Li R, Kuri B, et al. A gain-of-function mutation in DHT synthesis in castration-resistant prostate cancer. Cell 2013;154:1074-84.

81. Kallio HML, Hieta R, Latonen L, et al. Constitutively active androgen receptor splice variants AR-V3, AR-V7 and AR-V9 are coexpressed in castration-resistant prostate cancer metastases. Br J Cancer 2018;119:347-56.

82. Sieuwerts AM, Onstenk W, Kraan J, et al. AR splice variants in circulating tumor cells of patients with castration-resistant prostate cancer: relation with outcome to cabazitaxel. Mol Oncol 2019;13:1795-807.

83. Zhang T, Karsh LI, Nissenblatt MJ, Canfield SE. Androgen receptor splice variant, AR-V7, as a biomarker of resistance to androgen axistargeted therapies in advanced prostate cancer. Clin Genitourin Cancer 2020;18:1-10.

84. Khan T, Scott KF, Becker TM, et al. The prospect of identifying resistance mechanisms for castrate-resistant prostate cancer using circulating tumor cells: is epithelial-to-mesenchymal transition a key player? Prostate Cancer 2020;2020:7938280.

85. Shiota M, Fujimoto N, Kashiwagi E, Eto M. The role of nuclear receptors in prostate cancer. Cells 2019;8:602.

86. Luo XH, Liu JZ, Wang B, et al. KLF14 potentiates oxidative adaptation via modulating HO-1 signaling in castrate-resistant prostate cancer. Endocr Relat Cancer 2019;26:181-95.

87. Koike A, Robles BEF, da Silva Bonacini AG, et al. Thiol groups as a biomarker for the diagnosis and prognosis of prostate cancer. $S c i$ Rep 2020;10:9093.

88. Ghafar MA, Anastasiadis AG, Chen MW, et al. Acute hypoxia increases the aggressive characteristics and survival properties of prostate cancer cells. Prostate 2003;54:58-67.

89. Park SY, Kim YJ, Gao AC, et al. Hypoxia increases androgen receptor activity in prostate cancer cells. Cancer Res 2006;66:5121-9.

90. Lee YG, Nam Y, Shin KJ, et al. Androgen-induced expression of DRP1 regulates mitochondrial metabolic reprogramming in prostate cancer. Cancer Lett 2020;471:72-87.

91. Nguyen DP, Li J, Tewari AK. Inflammation and prostate cancer: the role of interleukin 6 (IL-6). BJU Int 2014;113:986-92.

92. Sharma J, Gray KP, Harshman LC, et al. Elevated IL-8, TNF- $\alpha$, and MCP-1 in men with metastatic prostate cancer starting androgendeprivation therapy (ADT) are associated with shorter time to castration-resistance and overall survival. Prostate 2014;74:820-8.

93. Sciarra A, Gentilucci A, Salciccia S, et al. Prognostic value of inflammation in prostate cancer progression and response to therapeutic: a 
critical review. J Inflamm (Lond) 2016;13:35.

94. Yamada Y, Sakamoto S, Rii J, et al. Prognostic value of an inflammatory index for patients with metastatic castration-resistant prostate cancer. Prostate 2020;80:559-69.

95. Pu H, Begemann DE, Kyprianou N. Aberrant TGF- $\beta$ signaling drives castration-resistant prostate cancer in a male mouse model of prostate tumorigenesis. Endocrinology 2017;158:1612-22.

96. Ottley EC, Nicholson HD, Gold EJ. Activin A regulates microRNAs and gene expression in LNCaP cells. Prostate 2016;76:951-63.

97. Eiro N, Fernandez-Gomez J, Sacristán R, et al. Stromal factors involved in human prostate cancer development, progression and castration resistance. J Cancer Res Clin Oncol 2017;143:351-9.

98. Malinen M, Niskanen EA, Kaikkonen MU, Palvimo JJ. Crosstalk between androgen and pro-inflammatory signaling remodels androgen receptor and NF- $\mathrm{\kappa B}$ cistrome to reprogram the prostate cancer cell transcriptome. Nucleic Acids Res 2017;45:619-30.

99. Erb HHH, Bodenbender J, Handle F, et al. Assessment of STAT5 as a potential therapy target in enzalutamide-resistant prostate cancer. PLoS One 2020;15:e0237248.

100. Sebastian T, Johnson PF. Stop and go: anti-proliferative and mitogenic functions of the transcription factor C/EBPbeta. Cell Cycle 2006;5:953-7.

101. Cao MQ, You AB, Cui W, et al. Cross talk between oxidative stress and hypoxia via thioredoxin and HIF-2 $\alpha$ drives metastasis of hepatocellular carcinoma. FASEB J 2020;34:5892-905.

102. Auyeung KK, Ko JK. Angiogenesis and oxidative stress in metastatic tumor progression: pathogenesis and novel therapeutic approach of colon cancer. Curr Pharm Des 2017;23:3952-61.

103. Culig Z. IL-6 causes multiple effects in androgen-sensitive and -insensitive prostate cancer cell lines. Expert Rev Endocrinol Metab 2011;6:327-32.

104. Culig Z, Puhr M. Interleukin-6: a multifunctional targetable cytokine in human prostate cancer. Mol Cell Endocrinol 2012;360:52-8.

105. Hudes G, Tagawa ST, Whang YE, et al. A phase 1 study of a chimeric monoclonal antibody against interleukin-6, siltuximab, combined with docetaxel in patients with metastatic castration-resistant prostate cancer. Invest New Drugs 2013;31:669-76.

106. Xu L, Chen X, Shen M, et al. Inhibition of IL-6-JAK/Stat3 signaling in castration-resistant prostate cancer cells enhances the NK cellmediated cytotoxicity via alteration of PD-L1/NKG2D ligand levels. Mol Oncol 2018;12:269-86.

107. Tanaka T, Narazaki M, Kishimoto T. IL-6 in inflammation, immunity, and disease. Cold Spring Harb Perspect Biol 2014;6:a016295.

108. Kumari N, Dwarakanath BS, Das A, Bhatt AN. Role of interleukin-6 in cancer progression and therapeutic resistance. Tumour Biol 2016;37:11553-72.

109. Zhang J, Pugh TD, Stebler B, Ershler WB, Keller ET. Orchiectomy increases bone marrow interleukin-6 levels in mice. Calcif Tissue Int 1998;62:219-26.

110. Lee SO, Lou W, Hou M, de Miguel F, Gerber L, Gao AC. Interleukin-6 promotes androgen-independent growth in LNCaP human prostate cancer cells. Clin Cancer Res 2003;9:370-6.

111. Adler HL, McCurdy MA, Kattan MW, Timme TL, Scardino PT, Thompson TC. Elevated levels of circulating interleukin-6 and transforming growth factor-beta1 in patients with metastatic prostatic carcinoma. $J$ Urol 1999;161:182-7.

112. Shariat SF, Andrews B, Kattan MW, Kim J, Wheeler TM, Slawin KM. Plasma levels of interleukin-6 and its soluble receptor are associated with prostate cancer progression and metastasis. Urology 2001;58:1008-15.

113. Hobisch A, Rogatsch H, Hittmair A, et al. Immunohistochemical localization of interleukin- 6 and its receptor in benign, premalignant and malignant prostate tissue. J Pathol 2000;191:239-44.

114. Luo Y, Zheng SG. Hall of fame among pro-inflammatory cytokines: interleukin-6 gene and its transcriptional regulation mechanisms. Front Immunol 2016;7:604.

115. Johnson DE, O'Keefe RA, Grandis JR. Targeting the IL-6/JAK/STAT3 signalling axis in cancer. Nat Rev Clin Oncol 2018;15:234-48.

116. Didion SP. Cellular and oxidative mechanisms associated with interleukin-6 signaling in the vasculature. Int J Mol Sci 2017;18:2563.

117. Liu J, Liu Y, Chen J, et al. The ROS-mediated activation of IL-6/STAT3 signaling pathway is involved in the 27-hydroxycholesterolinduced cellular senescence in nerve cells. Toxicol In Vitro 2017;45:10-8.

118. Mauer J, Denson JL, Brüning JC. Versatile functions for IL-6 in metabolism and cancer. Trends Immunol 2015;36:92-101.

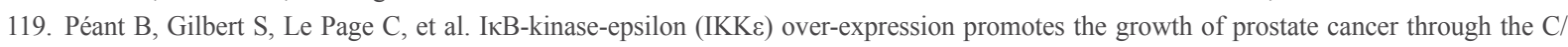
EBP- $\beta$ dependent activation of IL-6 gene expression. Oncotarget 2017;8:14487-501.

120. Xiao W, Hodge DR, Wang L, Yang X, Zhang X, Farrar WL. Co-operative functions between nuclear factors NFkappaB and CCAT/ enhancer-binding protein-beta (C/EBP-beta) regulate the IL-6 promoter in autocrine human prostate cancer cells. Prostate 2004;61:354-70.

121. Debelec-Butuner B, Alapinar C, Varisli L, et al. Inflammation-mediated abrogation of androgen signaling: an in vitro model of prostate cell inflammation. Mol Carcinog 2014;53:85-97.

122. Mohanty SK, Yagiz K, Pradhan D, et al. STAT3 and STAT5A are potential therapeutic targets in castration-resistant prostate cancer. Oncotarget 2017;8:85997-6010.

123. Kim MH, Fields J. Translationally regulated C/EBP beta isoform expression upregulates metastatic genes in hormone-independent prostate cancer cells. Prostate 2008;68:1362-71.

124. Barakat DJ, Zhang J, Barberi T, Denmeade SR, Friedman AD, Paz-Priel I. CCAAT/Enhancer binding protein $\beta$ controls androgendeprivation-induced senescence in prostate cancer cells. Oncogene 2015;34:5912-22.

125. Maina PK, Shao P, Liu Q, et al. c-MYC drives histone demethylase PHF8 during neuroendocrine differentiation and in castration-resistant prostate cancer. Oncotarget 2016;7:75585-602.

126. Jiang C, Masood M, Rasul A, et al. Altholactone inhibits NF-кB and STAT3 activation and induces reactive oxygen species-mediated 
apoptosis in prostate cancer DU145 Cells. Molecules 2017;22:240.

127. Nunes JJ, Pandey SK, Yadav A, Goel S, Ateeq B. Targeting NF-kappa B signaling by artesunate restores sensitivity of castrate-resistant prostate cancer cells to antiandrogens. Neoplasia 2017;19:333-45.

128. Tam L, McGlynn LM, Traynor P, Mukherjee R, Bartlett JM, Edwards J. Expression levels of the JAK/STAT pathway in the transition from hormone-sensitive to hormone-refractory prostate cancer. Br J Cancer 2007;97:378-83.

129. Liu C, Zhu Y, Lou W, Cui Y, Evans CP, Gao AC. Inhibition of constitutively active Stat3 reverses enzalutamide resistance in LNCaP derivative prostate cancer cells. Prostate 2014;74:201-9.

130. Dorff TB, Goldman B, Pinski JK, et al. Clinical and correlative results of SWOG S0354: a phase II trial of CNTO328 (siltuximab), a monoclonal antibody against interleukin-6, in chemotherapy-pretreated patients with castration-resistant prostate cancer. Clin Cancer Res 2010;16:3028-34

131. Culig Z, Puhr M. Interleukin-6 and prostate cancer: current developments and unsolved questions. Mol Cell Endocrinol 2018;462:25-30.

132. Burton GJ, Jauniaux E. Oxidative stress. Best Pract Res Clin Obstet Gynaecol 2011;25:287-99.

133. Radi R. Oxygen radicals, nitric oxide, and peroxynitrite: redox pathways in molecular medicine. Proc Natl Acad Sci U S A 2018;115:5839-48.

134. Schieber M, Chandel NS. ROS function in redox signaling and oxidative stress. Curr Biol 2014;24:R453-62.

135. Bryan S, Baregzay B, Spicer D, Singal PK, Khaper N. Redox-inflammatory synergy in the metabolic syndrome. Can J Physiol Pharmacol 2013;91:22-30.

136. Guang MHZ, Kavanagh EL, Dunne LP, et al. Targeting proteotoxic stress in cancer: a review of the role that protein quality control pathways play in oncogenesis. Cancers (Basel) 2019;11:66.

137. Ashkavand Z, Sarasija S, Ryan KC, Laboy JT, Norman KR. Corrupted ER-mitochondrial calcium homeostasis promotes the collapse of proteostasis. Aging Cell 2020;19:e13065.

138. Doghman-Bouguerra M, Lalli E. ER-mitochondria interactions: Both strength and weakness within cancer cells. Biochim Biophys Acto Mol Cell Res 2019;1866:650-62.

139. Xia M, Zhang Y, Jin K, Lu Z, Zeng Z, Xiong W. Communication between mitochondria and other organelles: a brand-new perspective on mitochondria in cancer. Cell Biosci 2019;9:27.

140. Cockfield JA, Schafer ZT. Antioxidant defenses: a context-specific vulnerability of cancer cells. Cancers (Basel) 2019;11:1208.

141. Acharya A, Das I, Chandhok D, Saha T. Redox regulation in cancer: a double-edged sword with therapeutic potential. Oxid Med Cell Longev 2010;3:23-34.

142. Arora H, Panara K, Kuchakulla M, et al. Alterations of tumor microenvironment by nitric oxide impedes castration-resistant prostate cancer growth. Proc Natl Acad Sci U S A. 2018;115:11298-303.

143. Fontana F, Moretti RM, Raimondi M, et al. $\delta$-Tocotrienol induces apoptosis, involving endoplasmic reticulum stress and autophagy, and paraptosis in prostate cancer cells. Cell Prolif 2019;52:e12576.

144. Lee S, Kim SM, Lee RT. Thioredoxin and thioredoxin target proteins: from molecular mechanisms to functional significance. Antioxid Redox Signal 2013;18:1165-207.

145. Bansal A, Simon MC. Glutathione metabolism in cancer progression and treatment resistance. J Cell Biol 2018;217:2291-8.

146. Meng Q, Shi S, Liang C, et al. Abrogation of glutathione peroxidase-1 drives EMT and chemoresistance in pancreatic cancer by activating ROS-mediated Akt/GSK3ß/Snail signaling. Oncogene 2018;37:5843-57.

147. Zalewska-Ziob M, Adamek B, Kasperczyk J, et al. Activity of antioxidant enzymes in the tumor and adjacent noncancerous tissues of non-small-cell lung cancer. Oxid Med Cell Longev 2019;2019:2901840.

148. Tonelli C, Chio IIC, Tuveson DA. Transcriptional regulation by Nrf2. Antioxid Redox Signal 2018;29:1727-45.

149. Sajadimajd S, Khazaei M. Oxidative stress and cancer: the role of Nrf2. Curr Cancer Drug Targets 2018;18:538-57.

150. Schultz MA, Hagan SS, Datta A, et al. Nrf1 and Nrf2 transcription factors regulate androgen receptor transactivation in prostate cancer cells. PLoS One 2014;9:e87204.

151. Schultz MA, Abdel-Mageed AB, Mondal D. The nrf1 and nrf2 balance in oxidative stress regulation and androgen signaling in prostate cancer cells. Cancers (Basel) 2010;2:1354-78.

152. Sova M, Saso L. Design and development of Nrf2 modulators for cancer chemoprevention and therapy: a review. Drug Des Devel Ther 2018;12:3181-97.

153. Menegon S, Columbano A, Giordano S. The dual roles of NRF2 in cancer. Trends Mol Med 2016;22:578-93.

154. Aggarwal V, Tuli HS, Varol A, et al. Role of reactive oxygen species in cancer progression: molecular mechanisms and recent advancements. Biomolecules 2019;9:735.

155. Perillo B, Di Donato M, Pezone A, et al. ROS in cancer therapy: the bright side of the moon. Exp Mol Med 2020;52:192-203.

156. Zhang J, Wang X, Vikash V, et al. ROS and ROS-mediated cellular signaling. Oxid Med Cell Longev. 2016;2016:4350965.

157. Shukla S, Srivastava JK, Shankar E, et al. Oxidative stress and antioxidant status in high-risk prostate cancer subjects. Diagnostics (Basel) 2020;10:126.

158. Shiota M, Yokomizo A, Naito S. Oxidative stress and androgen receptor signaling in the development and progression of castrationresistant prostate cancer. Free Radic Biol Med 2011;51:1320-8.

159. Shiota M, Yokomizo A, Tada Y, et al. Castration resistance of prostate cancer cells caused by castration-induced oxidative stress through Twist1 and androgen receptor overexpression. Oncogene 2010;29:237-50.

160. Shiota M, Fujimoto N, Itsumi M, et al. Gene polymorphisms in antioxidant enzymes correlate with the efficacy of androgen-deprivation therapy for prostate cancer with implications of oxidative stress. Ann Oncol 2017;28:569-75. 
161. Pinthus JH, Bryskin I, Trachtenberg J, et al. Androgen induces adaptation to oxidative stress in prostate cancer: implications for treatment with radiation therapy. Neoplasia 2007;9:68-80.

162. Shiota M, Yokomizo A, Naito S. Pro-survival and anti-apoptotic properties of androgen receptor signaling by oxidative stress promote treatment resistance in prostate cancer. Endocr Relat Cancer 2012;19:R243-53.

163. Fajardo AM, MacKenzie DA, Olguin SL, Scariano JK, Rabinowitz I, Thompson TA. Antioxidants abrogate alpha-tocopherylquinonemediated down-regulation of the androgen receptor in androgen-responsive prostate cancer cells. PLoS One 2016;11:e0151525.

164. Lu JP, Monardo L, Bryskin I, et al. Androgens induce oxidative stress and radiation resistance in prostate cancer cells though NADPH oxidase. Prostate Cancer Prostatic Dis 2010;13:39-46.

165. Höll M, Koziel R, Schäfer G, et al. ROS signaling by NADPH oxidase 5 modulates the proliferation and survival of prostate carcinoma cells. Mol Carcinog 2016;55:27-39.

166. Wu QQ, Zheng B, Weng GB, et al. Downregulated NOX4 underlies a novel inhibitory role of microRNA-137 in prostate cancer. $J$ Cell Biochem 2019;120:10215-27.

167. Schmid-Alliana A, Schmid-Antomarchi H, Al-Sahlanee R, Lagadec P, Scimeca JC, Verron E. Understanding the progression of bone metastases to identify novel therapeutic targets. Int J Mol Sci 2018;19:148.

168. Wang Y, Singhal U, Qiao Y, et al. Wnt signaling drives prostate cancer bone metastatic tropism and invasion. Transl Oncol 2020;13:100747.

169. Rana K, Davey RA, Zajac JD. Human androgen deficiency: insights gained from androgen receptor knockout mouse models. Asian $J$ Androl 2014;16:169-77.

170. Russell PK, Mangiafico S, Fam BC, et al. The androgen receptor in bone marrow progenitor cells negatively regulates fat mass. $J$ Endocrinol 2018;237:15-27.

171. Bielecki B, Mattern C, Ghoumari AM, et al. Unexpected central role of the androgen receptor in the spontaneous regeneration of myelin. Proc Natl Acad Sci U S A 2016;113:14829-34.

172. Abi-Ghanem C, Robison LS, Zuloaga KL. Androgens' effects on cerebrovascular function in health and disease. Biol Sex Differ 2020;11:35.

173. Vomund S, Schäfer A, Parnham MJ, Brüne B, von Knethen A. Nrf2, the master regulator of anti-oxidative responses. Int J Mol Sci 2017;18:2772.

174. Bellezza I, Giambanco I, Minelli A, Donato R. Nrf2-Keap1 signaling in oxidative and reductive stress. Biochim Biophys Acta Mol Cell Res 2018;1865:721-33.

175. Satoh H, Moriguchi T, Taguchi K, et al. Nrf2-deficiency creates a responsive microenvironment for metastasis to the lung. Carcinogenesis 2010;31:1833-43.

176. Khor TO, Huang MT, Prawan A, et al. Increased susceptibility of Nrf2 knockout mice to colitis-associated colorectal cancer. Cancer Prev Res (Phila) 2008;1:187-91.

177. Xue D, Zhou C, Shi Y, Lu H, Xu R, He X. Nuclear transcription factor Nrf2 suppresses prostate cancer cells growth and migration through upregulating ferroportin. Oncotarget 2016;7:78804-12.

178. Zhou Y, Wu H, Zhao M, Chang C, Lu Q. The bach family of transcription factors: a comprehensive review. Clin Rev Allergy Immunol 2016;50:345-56.

179. Klotz LO, Sánchez-Ramos C, Prieto-Arroyo I, Urbánek P, Steinbrenner H, Monsalve M. Redox regulation of FoxO transcription factors. Redox Biol 2015;6:51-72.

180. Robledinos-Antón N, Fernández-Ginés R, Manda G, Cuadrado A. Activators and inhibitors of NRF2: a review of their potential for clinical development. Oxid Med Cell Longev 2019;2019:9372182.

181. Cuadrado A, Rojo AI, Wells G, et al. Therapeutic targeting of the NRF2 and KEAP1 partnership in chronic diseases. Nat Rev Drug Discov 2019;18:295-317.

182. Shin IS, Hong J, Jeon CM, et al. Diallyl-disulfide, an organosulfur compound of garlic, attenuates airway inflammation via activation of the Nrf-2/HO-1 pathway and NF-kappaB suppression. Food Chem Toxicol 2013;62:506-13.

183. Macías-Pérez JR, Vázquez-López BJ, Muñoz-Ortega MH, et al. Curcumin and $\alpha / \beta$-adrenergic antagonists cotreatment reverse liver cirrhosis in hamsters: participation of Nrf-2 and NF- $\kappa$ B. J Immunol Res 2019;2019:3019794.

184. Impellizzeri D, Esposito E, Attley J, Cuzzocrea S. Targeting inflammation: new therapeutic approaches in chronic kidney disease (CKD). Pharmacol Res 2014;81:91-102.

185. Alam J, Stewart D, Touchard C, Boinapally S, Choi AM, Cook JL. Nrf2, a Cap'n'Collar transcription factor, regulates induction of the heme oxygenase-1 gene. J Biol Chem 1999;274:26071-8.

186. Gong P, Stewart D, Hu B, Vinson C, Alam J. Multiple basic-leucine zipper proteins regulate induction of the mouse heme oxygenase-1 gene by arsenite. Arch Biochem Biophys 2002;405:265-74.

187. Dhakshinamoorthy S, Jaiswal AK. c-Maf negatively regulates ARE-mediated detoxifying enzyme genes expression and anti-oxidant induction. Oncogene 2002;21:5301-12.

188. Krajka-Kuźniak V, Paluszczak J, Baer-Dubowska W. The Nrf2-ARE signaling pathway: An update on its regulation and possible role in cancer prevention and treatment. Pharmacol Rep 2017;69:393-402.

189. Raghunath A, Sundarraj K, Nagarajan R, et al. Antioxidant response elements: discovery, classes, regulation and potential applications. Redox Biol 2018;17:297-314.

190. Arlt A, Sebens S, Krebs S, et al. Inhibition of the Nrf2 transcription factor by the alkaloid trigonelline renders pancreatic cancer cells more susceptible to apoptosis through decreased proteasomal gene expression and proteasome activity. Oncogene 2013;32:4825-35. 
191. Lee YJ, Lee DM, Lee SH. Nrf2 expression and apoptosis in quercetin-treated malignant mesothelioma cells. Mol Cells 2015;38:416-25.

192. Feng T, Zhao R, Sun F, et al. TXNDC9 regulates oxidative stress-induced androgen receptor signaling to promote prostate cancer progression. Oncogene 2020;39:356-67.

193. Fajardo AM, MacKenzie DA, Ji M, et al. The curcumin analog ca27 down-regulates androgen receptor through an oxidative stress mediated mechanism in human prostate cancer cells. Prostate 2012;72:612-25.

194. Liu GH, Qu J, Shen X. NF-kappaB/p65 antagonizes Nrf2-ARE pathway by depriving CBP from Nrf2 and facilitating recruitment of HDAC3 to MafK. Biochim Biophys Acta 2008;1783:713-27.

195. Li W, Khor TO, Xu C, et al. Activation of Nrf2-antioxidant signaling attenuates NFkappaB-inflammatory response and elicits apoptosis. Biochem Pharmacol 2008;76:1485-9.

196. Yu M, Li H, Liu Q, et al. Nuclear factor p65 interacts with Keap1 to repress the Nrf2-ARE pathway. Cell Signal 2011;23:883-92.

197. Jin R, Yamashita H, Yu X, et al. Inhibition of NF-kappa B signaling restores responsiveness of castrate-resistant prostate cancer cells to anti-androgen treatment by decreasing androgen receptor-variant expression. Oncogene 2015;34:3700-10.

198. Qin DJ, Tang CX, Yang L, et al. Hsp90 is a novel target molecule of CDDO-Me in inhibiting proliferation of ovarian cancer cells. PLoS One 2015;10:e132337.

199. Cuadrado A, Manda G, Hassan A, et al. Transcription factor NRF2 as a therapeutic target for chronic diseases: a systems medicine approach. Pharmacol Rev 2018;70:348-83.

200. Magesh S, Chen Y, Hu L. Small molecule modulators of Keap1-Nrf2-ARE pathway as potential preventive and therapeutic agents. Med Res Rev 2012;32:687-726.

201. Hur W, Gray NS. Small molecule modulators of antioxidant response pathway. Curr Opin Chem Biol 2011;15:162-73.

202. Jiménez-Osorio AS, González-Reyes S, Pedraza-Chaverri J. Natural Nrf2 activators in diabetes. Clin Chim Acta 2015;448:182-92.

203. Houghton CA, Fassett RG, Coombes JS. Sulforaphane and other nutrigenomic Nrf2 activators: can the Clinician's expectation be matched by the reality? Oxid Med Cell Longev 2016;2016:7857186.

204. Zhou H, Wang Y, You Q, Jiang Z. Recent progress in the development of small molecule Nrf2 activators: a patent review (2017-present). Expert Opin Ther Pat 2020;30:209-25.

205. Altmeyer PJ, Matthes U, Pawlak F, et al. Antipsoriatic effect of fumaric acid derivatives. Results of a multicenter double-blind study in 100 patients. J Am Acad Dermatol 1994;30:977-81.

206. Mrowietz U, Christophers E, Altmeyer P. Treatment of psoriasis with fumaric acid esters: results of a prospective multicentre study. German Multicentre Study. Br J Dermatol 1998;138:456-60.

207. Mrowietz U, Szepietowski JC, Loewe R, et al. Efficacy and safety of LAS41008 (dimethyl fumarate) in adults with moderate-tosevere chronic plaque psoriasis: a randomized, double-blind, Fumaderm((R)) - and placebo-controlled trial (BRIDGE). Br J Dermatol 2017; 176:615-23.

208. Xu Z, Zhang F, Sun F, Gu K, Dong S, He D. Dimethyl fumarate for multiple sclerosis. Cochrane Database Syst Rev 2015;(4):CD011076.

209. Linker RA, Lee DH, Ryan S, et al. Fumaric acid esters exert neuroprotective effects in neuroinflammation via activation of the Nrf2 antioxidant pathway. Brain 2011;134:678-92.

210. Blewett MM, Xie J, Zaro BW, et al. Chemical proteomic map of dimethyl fumarate-sensitive cysteines in primary human T cells. Sci Signal 2016;9:rs10.

211. Gillard GO, Collette B, Anderson J, et al. DMF, but not other fumarates, inhibits NF-kB activity in vitro in an Nrf2-independent manner. J Neuroimmunol 2015;283:74-85.

212. Chen H, Assmann JC, Krenz A, et al. Hydroxycarboxylic acid receptor 2 mediates dimethyl fumarate's protective effect in EAE. $J$ Clin Invest 2014;124:2188-92.

213. Tan SM, Sharma A, Stefanovic N, et al. Derivative of bardoxolone methyl, dh404, in an inverse dose-dependent manner lessens diabetesassociated atherosclerosis and improves diabetic kidney disease. Diabetes 2014;63:3091-103.

214.Kastrati I, Siklos MI, Calderon-Gierszal EL, et al. Dimethyl fumarate inhibits the nuclear factor $\mathrm{kB}$ pathway in breast cancer cells by covalent modification of p65 protein. J Biol Chem 2016;291:3639-47.

215. Johnson NM, Egner PA, Baxter VK, et al. Complete protection against aflatoxin B(1)-induced liver cancer with a triterpenoid: DNA adduct dosimetry, molecular signature, and genotoxicity threshold. Cancer Prev Res (Phila) 2014;7:658-65.

216. Nachliely M, Trachtenberg A, Khalfin B, et al. Dimethyl fumarate and vitamin D derivatives cooperatively enhance VDR and Nrf2 signaling in differentiating AML cells in vitro and inhibit leukemia progression in a xenograft mouse model. J Steroid Biochem Mol Biol 2019;188:8-16.

217. Ahmadi-Beni R, Najafi A, Savar SM, Mohebbi N, Khoshnevisan A. Role of dimethyl fumarate in the treatment of glioblastoma multiforme: a review article. Iran J Neurol 2019;18:127-33.

218. Kastrati I, Siklos MI, Calderon-Gierszal EL, et al. Dimethyl fumarate inhibits the nuclear factor $\kappa \mathrm{B}$ pathway in breast cancer cells by covalent modification of p65 protein. J Biol Chem 2016;291:3639-47.

219. Bennett Saidu NE, Bretagne M, Mansuet AL, et al. Dimethyl fumarate is highly cytotoxic in KRAS mutated cancer cells but spares nontumorigenic cells. Oncotarget 2018;9:9088-99.

220. Khurana N, Talwar S, Chandra PK, et al. Sulforaphane increases the efficacy of anti-androgens by rapidly decreasing androgen receptor levels in prostate cancer cells. Int J Oncol 2016;49:1609-19.

221. Nare B, Smith JM, Prichard RK. Mechanisms of inactivation of Schistosoma mansoni and mammalian glutathione S-transferase activity by the antischistosomal drug oltipraz. Biochem Pharmacol 1992;43:1345-51.

222. Click RE. Anticancer activity and chemoprevention of xenobiotic organosulfurs in preclinical model systems. Oncol Discov 
2013;1:10.7243/2052-6199-1-4.

223. Shimozono R, Asaoka Y, Yoshizawa Y, et al. Nrf2 activators attenuate the progression of nonalcoholic steatohepatitis-related fibrosis in a dietary rat model. Mol Pharmacol 2013;84:62-70.

224. Yagishita Y, Gatbonton-Schwager TN, McCallum ML, Kensler TW. Current Landscape of NRF2 Biomarkers in Clinical Trials. Antioxidants (Basel) 2020;9:E716.

225. Qiu P, Man S, Li J, et al. Overdose intake of curcumin initiates the unbalanced state of bodies. J Agric Food Chem 2016;64:2765-71.

226. Chuengsamarn S, Rattanamongkolgul S, Phonrat B, et al. Reduction of atherogenic risk in patients with type 2 diabetes by curcuminoid extract: a randomized controlled trial. J Nutr Biochem 2014;25:144-50.

227. Na LX, Yan BL, Jiang S, Cui HL, Li Y, Sun CH. Curcuminoids target decreasing serum adipocyte-fatty acid binding protein levels in their glucose-lowering effect in patients with type 2 diabetes. Biomed Environ Sci 2014;27:902-6.

228. Shishodia S, Chaturvedi MM, Aggarwal BB. Role of curcumin in cancer therapy. Curr Probl Cancer 2007;31:243-305.

229. Woo JH, Kim YH, Choi YJ, et al. Molecular mechanisms of curcumin-induced cytotoxicity: induction of apoptosis through generation of reactive oxygen species, down-regulation of $\mathrm{Bcl}-\mathrm{XL}$ and IAP, the release of cytochrome $\mathrm{c}$ and inhibition of Akt. Carcinogenesis 2003;24:1199-208.

230. Lin SS, Huang HP, Yang JS, et al. DNA damage and endoplasmic reticulum stress mediated curcumin-induced cell cycle arrest and apoptosis in human lung carcinoma A-549 cells through the activation caspases cascade- and mitochondrial-dependent pathway. Cancer Lett 2008;272:77-90.

231. Basile V, Belluti S, Ferrari E, et al. bis-Dehydroxy-curcumin triggers mitochondrial-associated cell death in human colon cancer cells through ER-stress induced autophagy. PLoS One 2013;8:e53664.

232. Yin H, Guo R, Xu Y, et al. Synergistic antitumor efficiency of docetaxel and curcumin against lung cancer. Acta Biochim Biophys Sin (Shanghai) 2012;44:147-53.

233. Abd Wahab NA, Lajis NH, Abas F, Othman I, Naidu R. Mechanism of anti-cancer activity of curcumin on androgen-dependent and androgen-independent prostate cancer. Nutrients 2020;12:679.

234. Li W, Su ZY, Guo Y, et al. Curcumin derivative epigenetically reactivates Nrf2 antioxidative stress signaling in mouse prostate cancer TRAMP C1 cells. Chem Res Toxicol 2018;31:88-96.

235. Hong JH, Lee G, Choi HY. Effect of curcumin on the interaction between androgen receptor and Wnt/ $\beta$-catenin in LNCaP xenografts. Korean J Urol 2015;56:656-65.

236. Mathur A, Abd Elmageed ZY, Liu X, et al. Subverting ER-stress towards apoptosis by nelfinavir and curcumin coexposure augments docetaxel efficacy in castration resistant prostate cancer cells. PLoS One 2014;9:e103109.

237. Nakamura K, Yasunaga Y, Segawa T, et al. Curcumin down-regulates AR gene expression and activation in prostate cancer cell lines. Int J Oncol 2002;21:825-30.

238. Fontana F, Raimondi M, Marzagalli M, Di Domizio A, Limonta P. Natural compounds in prostate cancer prevention and treatment: mechanisms of action and molecular targets. Cells 2020;9:460.

239. Dong S, Alahari SK. Combination treatment of bicalutamide and curcumin has a strong therapeutic effect on androgen receptor-positive triple-negative breast cancers. Anticancer Drugs 2020;31:359-67.

240. Pan MH, Huang TM, Lin JK. Biotransformation of curcumin through reduction and glucuronidation in mice. Drug Metab Dispos 1999;27:486-94.

241. Lin TH, Lee SO, Niu Y, et al. Differential androgen deprivation therapies with anti-androgens casodex/bicalutamide or MDV3100/ Enzalutamide versus anti-androgen receptor ASC-J9(R) Lead to promotion versus suppression of prostate cancer metastasis. J Biol Chem 2013;288:19359-69.

242. Hardwick J, Taylor J, Mehta M, et al. Targeting cancer using curcumin encapsulated vesicular drug delivery systems. Curr Pharm Des 2020; doi: 10.2174/1381612826666200728151610.

243. Yamashita S, Lai KP, Chuang KL, et al. ASC-J9 suppresses castration-resistant prostate cancer growth through degradation of full-length and splice variant androgen receptors. Neoplasia 2012;14:74-83.

244. Abbaoui B, Lucas CR, Riedl KM, Clinton SK, Mortazavi A. Cruciferous vegetables, isothiocyanates, and bladder cancer prevention. Mol Nutr Food Res 2018;62:e1800079.

245. Xu C, Shen G, Chen C, Gélinas C, Kong AN. Suppression of NF-kappaB and NF-kappaB-regulated gene expression by sulforaphane and PEITC through IkappaBalpha, IKK pathway in human prostate cancer PC-3 cells. Oncogene 2005;24:4486-95.

246. Naujokat C, McKee DL. The "Big Five" phytochemicals targeting cancer stem cells: Curcumin, EGCG, Sulforaphane, resveratrol and genistein. Curr Med Chem 2020; doi: 10.2174/0929867327666200228110738.

247. Houghton CA. Sulforaphane: Its "Coming of Age" as a clinically relevant nutraceutical in the prevention and treatment of chronic disease. Oxid Med Cell Longev 2019;2019:2716870.

248. Jiang X, Bai Y, Zhang Z, Xin Y, Cai L. Protection by sulforaphane from type 1 diabetes-induced testicular apoptosis is associated with the up-regulation of Nrf2 expression and function. Toxicol Appl Pharmacol 2014;279:198-210.

249. Artaud-Macari E, Goven D, Brayer S, et al. Nuclear factor erythroid 2-related factor 2 nuclear translocation induces myofibroblastic dedifferentiation in idiopathic pulmonary fibrosis. Antioxid Redox Signal 2013;18:66-79.

250. Fois AG, Paliogiannis P, Sotgia S, et al. Evaluation of oxidative stress biomarkers in idiopathic pulmonary fibrosis and therapeutic applications: a systematic review. Respir Res 2018;19:51.

251. Jiang T, Tian F, Zheng H, et al. Nrf2 suppresses lupus nephritis through inhibition of oxidative injury and the NF- $\mathrm{KB}-\mathrm{mediated}$ inflammatory response. Kidney Int 2014;85:333-43. 
252. Singh KB, Hahm ER, Alumkal JJ, et al. Reversal of the Warburg phenomenon in chemoprevention of prostate cancer by sulforaphane. Carcinogenesis 2019;40:1545-56.

253. Ullah MF. Sulforaphane (SFN): an isothiocyanate in a cancer chemoprevention paradigm. Medicines (Basel) 2015;2:141-56.

254. Kamal MM, Akter S, Lin CN, Nazzal S. Sulforaphane as an anticancer molecule: mechanisms of action, synergistic effects, enhancement of drug safety, and delivery systems. Arch Pharm Res 2020;43:371-84.

255. Zhang C, Su ZY, Khor TO, Shu L, Kong AN. Sulforaphane enhances Nrf2 expression in prostate cancer TRAMP C1 cells through epigenetic regulation. Biochem Pharmacol 2013;85:1398-404.

256. Beaver LM, Löhr CV, Clarke JD, et al. Broccoli sprouts delay prostate cancer formation and decrease prostate cancer severity with a concurrent decrease in HDAC3 protein expression in transgenic adenocarcinoma of the mouse prostate (TRAMP) mice. Curr Dev Nutr 2017;2:nzy002.

257. Keum YS, Khor TO, Lin W, et al. Pharmacokinetics and pharmacodynamics of broccoli sprouts on the suppression of prostate cancer in transgenic adenocarcinoma of mouse prostate (TRAMP) mice: implication of induction of Nrf2, HO-1 and apoptosis and the suppression of Akt-dependent kinase pathway. Pharm Res 2009;26:2324-31.

258. Farkhondeh T, Folgado SL, Pourbagher-Shahri AM, Ashrafizadeh M, Samarghandian S. The therapeutic effect of resveratrol: focusing on the Nrf2 signaling pathway. Biomed Pharmacother 2020;127:110234.

259. Berman AY, Motechin RA, Wiesenfeld MY, Holz MK. The therapeutic potential of resveratrol: a review of clinical trials. NPJ Precis Oncol 2017;1:35.

260. Xia N, Daiber A, Förstermann U, Li H. Antioxidant effects of resveratrol in the cardiovascular system. Br J Pharmacol 2017;174:1633-46.

261. Ungvari Z, Bagi Z, Feher A, et al. Resveratrol confers endothelial protection via activation of the antioxidant transcription factor Nrf2. Am J Physiol Heart Circ Physiol 2010;299:H18-24.

262. Ghanim H, Sia CL, Korzeniewski K, et al. A resveratrol and polyphenol preparation suppresses oxidative and inflammatory stress response to a high-fat, high-carbohydrate meal. J Clin Endocrinol Metab 2011;96:1409-14.

263. Ávila-Gálvez MÁ, Giménez-Bastida JA, Espín JC, González-Sarrías A. Dietary phenolics against breast cancer. A critical evidence-based review and future perspectives. Int J Mol Sci 2020;21:E5718.

264. Ding S, Xu S, Fang J, Jiang H. The protective effect of polyphenols for colorectal cancer. Front Immunol 2020;11:1407.

265. Kumar A, Rimando AM, Levenson AS. Resveratrol and pterostilbene as a microRNA-mediated chemopreventive and therapeutic strategy in prostate cancer. Ann N Y Acad Sci 2017;1403:15-26.

266. Wilson S, Cavero L, Tong D, et al. Resveratrol enhances polyubiquitination-mediated ARV7 degradation in prostate cancer cells. Oncotarget 2017;8:54683-93.

267. De Amicis F, Chimento A, Montalto FI, Casaburi I, Sirianni R, Pezzi V. Steroid receptor signallings as targets for resveratrol actions in breast and prostate cancer. Int J Mol Sci 2019;20:1087.

268. Shanmugam MK, Nguyen AH, Kumar AP, Tan BK, Sethi G. Targeted inhibition of tumor proliferation, survival, and metastasis by pentacyclic triterpenoids: potential role in prevention and therapy of cancer. Cancer Lett 2012;320:158-70.

269. Pergola PE, Raskin P, Toto RD, et al. Bardoxolone methyl and kidney function in CKD with type 2 diabetes. $N$ Engl J Med 2011;365:327-36.

270. Chin MP, Wrolstad D, Bakris GL, et al. Risk factors for heart failure in patients with type 2 diabetes mellitus and stage 4 chronic kidney disease treated with bardoxolone methyl. J Card Fail 2014;20:953-8.

271. Wang YY, Yang YX, Zhe H, He ZX, Zhou SF. Bardoxolone methyl (CDDO-Me) as a therapeutic agent: an update on its pharmacokinetic and pharmacodynamic properties. Drug Des Devel Ther 2014;8:2075-88.

272. Baigent C, Lennon R. Should we increase GFR with Bardoxolone in Alport syndrome? J Am Soc Nephrol 2018;29:357-9.

273. Wang YY, Zhe H, Zhao R. Preclinical evidences toward the use of triterpenoid CDDO-Me for solid cancer prevention and treatment. Mol Cancer 2014;13:30.

274. Deeb D, Gao X, Jiang H, Dulchavsky SA, Gautam SC. Oleanane triterpenoid CDDO-Me inhibits growth and induces apoptosis in prostate cancer cells by independently targeting pro-survival Akt and mTOR. Prostate 2009;69:851-60.

275. Kim EH, Deng C, Sporn MB, et al. CDDO-methyl ester delays breast cancer development in BRCA1-mutated mice. Cancer Prev Res (Phila) 2012;5:89-97.

276. Gao X, Liu Y, Deeb D, et al. Synthetic oleanane triterpenoid, CDDO-Me, induces apoptosis in ovarian cancer cells by inhibiting prosurvival AKT/NF-kB/mTOR signaling. Anticancer Res 2011;31:3673-81.

277. Liby K, Royce DB, Williams CR, et al. The synthetic triterpenoids CDDO-methyl ester and CDDO-ethyl amide prevent lung cancer induced by vinyl carbamate in A/J mice. Cancer Res 2007;67:2414-9.

278. Liby KT, Royce DB, Risingsong R, et al. Synthetic triterpenoids prolong survival in a transgenic mouse model of pancreatic cancer. Cancer Prev Res (Phila) 2010;3:1427-34.

279. Ryu K, Susa M, Choy E, et al. Oleanane triterpenoid CDDO-Me induces apoptosis in multidrug resistant osteosarcoma cells through inhibition of Stat3 pathway. BMC Cancer 2010;10:187.

280. Dinkova-Kostova AT, Liby KT, Stephenson KK, et al. Extremely potent triterpenoid inducers of the phase 2 response: correlations of protection against oxidant and inflammatory stress. Proc Natl Acad Sci U S A 2005;102:4584-9.

281. Hong DS, Kurzrock R, Supko JG, et al. A phase I first-in-human trial of bardoxolone methyl in patients with advanced solid tumors and lymphomas. Clin Cancer Res 2012;18:3396-406.

282. Gao X, Deeb D, Liu Y, et al. Prevention of prostate cancer with oleanane synthetic triterpenoid CDDO-Me in the TRAMP mouse model of prostate cancer. Cancers (Basel) 2011;3:3353-69. 
283. Liu Y, Gao X, Deeb D, Arbab AS, Gautam SC. Telomerase reverse transcriptase (TERT) is a therapeutic target of oleanane triterpenoid CDDO-Me in prostate cancer. Molecules 2012;17:14795-809.

284. Madsen KL, Buch AE, Cohen BH, et al. Safety and efficacy of omaveloxolone in patients with mitochondrial myopathy: MOTOR trial. Neurology 2020;94:e687-98.

285. Probst BL, Trevino I, McCauley L, et al. RTA 408, A novel synthetic triterpenoid with broad anticancer and anti-inflammatory activity. PLoS One 2015; 10:e122942.

286. Abeti R, Baccaro A, Esteras N, Giunti P. Novel Nrf2-inducer prevents mitochondrial defects and oxidative stress in Friedreich's ataxia models. Front Cell Neurosci 2018;12:188.

287. Rabbani PS, Ellison T, Waqas B, et al. Targeted Nrf2 activation therapy with RTA 408 enhances regenerative capacity of diabetic wounds. Diabetes Res Clin Pract 2018;139:11-23.

288. Sun X, Xie Z, Hu B, et al. The Nrf2 activator RTA-408 attenuates osteoclastogenesis by inhibiting STING dependent NF-kb signaling. Redox Biol 2020;28:101309.

289. Reisman SA, Ferguson DA, Lee CI, Proksch JW. Omaveloxolone and TX63682 are hepatoprotective in the STAM mouse model of nonalcoholic steatohepatitis. J Biochem Mol Toxicol 2020; 22526.

290. Rodriguez-Duarte J, Dapueto R, Galliussi G, et al. Electrophilic nitroalkene-tocopherol derivatives: synthesis, physicochemical characterization and evaluation of anti-inflammatory signaling responses. Sci Rep 2018;8:12784.

291. Schopfer FJ, Vitturi DA, Jorkasky DK, Freeman BA. Nitro-fatty acids: new drug candidates for chronic inflammatory and fibrotic diseases. Nitric Oxide 2018;79:31-7.

292. Zhang P, Singh A, Yegnasubramanian S, et al. Loss of Kelch-like ECH-associated protein 1 function in prostate cancer cells causes chemoresistance and radioresistance and promotes tumor growth. Mol Cancer The 2010;9:336-46.

293. Ciamporcero E, Daga M, Pizzimenti S, et al. Crosstalk between Nrf2 and YAP contributes to maintaining the antioxidant potential and chemoresistance in bladder cancer. Free Radic Biol Med 2018;115:447-57.

294. Ischia J, Saad F, Gleave M. The promise of heat shock protein inhibitors in the treatment of castration resistant prostate cancer. Curr Opin Urol 2013;23:194-200.

295. Azad AA, Zoubeidi A, Gleave ME, Chi KN. Targeting heat shock proteins in metastatic castration-resistant prostate cancer. Nat Rev Urol 2015;12:26-36.

296. Fernandez-Salas E, Wang S, Chinnaiyan AM. Role of BET proteins in castration-resistant prostate cancer. Drug Discov Today Technol 2016;19:29-38.

297. Urbanucci A, Mills IG. Bromodomain-containing proteins in prostate cancer. Mol Cell Endocrinol 2018;462:31-40. 